\title{
Working
}

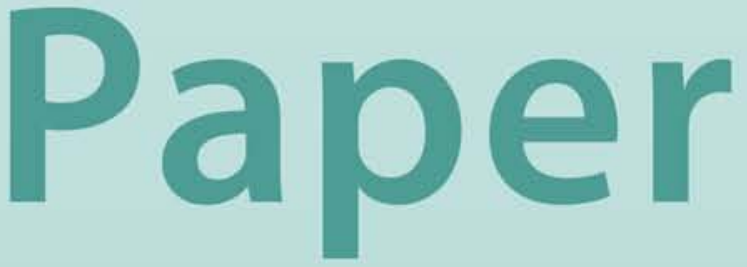




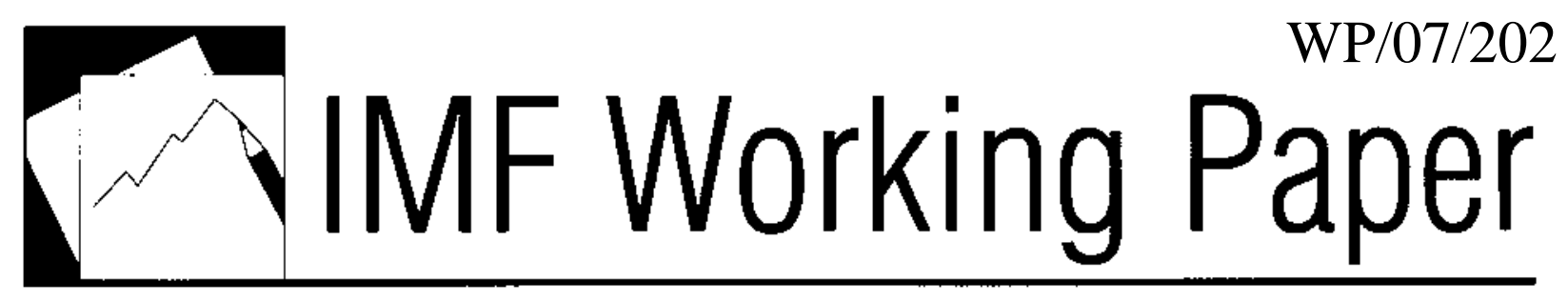

\section{A Party without a Hangover? On the Effects of U.S. Government Deficits}

Michael Kumhof and Douglas Laxton 


\title{
IMF Working Paper
}

\author{
Research Department
}

\begin{abstract}
A Party without a Hangover? On the Effects of U.S. Government Deficits
Prepared by Michael Kumhof and Douglas Laxton
\end{abstract}

Authorized for distribution by Gian Maria Milesi-Ferretti

August 2007

\begin{abstract}

\section{This Working Paper should not be reported as representing the views of the IMF.}

The views expressed in this Working Paper are those of the author(s) and do not necessarily represent those of the IMF or IMF policy. Working Papers describe research in progress by the author(s) and are published to elicit comments and to further debate.
\end{abstract}

This paper develops a 2-country New Keynesian overlapping generations model suitable for the joint evaluation of monetary and fiscal policies. We show that a permanent increase in U.S. government deficits raises the world real interest rate and significantly increases U.S. current account deficits, especially in the medium- to long-run. A simultaneous increase in non-U.S. savings lowers the world real interest rate and further increases U.S. current account deficits. We show that conventional infinite horizon models are ill-equipped to deal with issues that involve permanent changes in public or private sector savings rates.

JEL Classification Numbers:E62; F41; F42; H30; H63

Keywords: Finite Lives; Distortionary Taxes; Government Debt

Authors’ E-Mail Addresses: mkumhof@imf.org; dlaxton@imf.org 


\section{Contents}

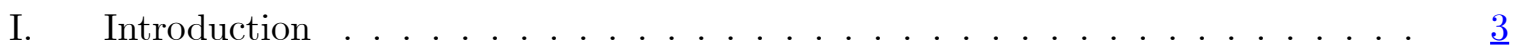

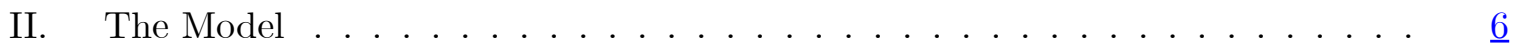

A. Households ......................... $\underline{8}$

1. Overlapping Generations Households . . . . . . . . . $\underline{8}$

2. Liquidity Constrained Households . . . . . . . . . . . . . $\underline{12}$

3. Aggregate Household Sector . . . . . . . . . . . . . . . . $\underline{12}$

B. Firms and Unions . . . . . . . . . . . . . . . . . $\underline{12}$

1. Manufacturers ..................... 13

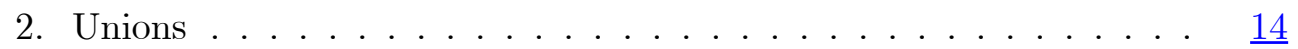

3. Import Agents . . . . . . . . . . . . . . . . . . 14

4. Distributors .................... 15

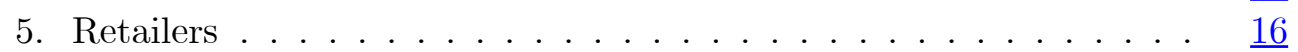

C. Government . . . . . . . . . . . . . . . $\underline{16}$

1. Fiscal Policy . . . . . . . . . . . . . . . . 16

2. Monetary Policy . . . . . . . . . . . . . . . . 17

D. Equilibrium and Balance of Payments . . . . . . . . . . . $\underline{17}$

III. Calibration ...................... 18

IV. Implications of U.S. Government Deficits . . . . . . . . . . . . . . . . $\underline{21}$

A. Useful Steady-State Relationships . . . . . . . . . . . . . . . $\underline{21}$

B. The Quantitative Predictions of the Two Models . . . . . . . . . . . $\underline{22}$

V. Implications of Government Spending Cuts . . . . . . . . . . . $\underline{25}$

VI. Implications of Private Sector Savings Behavior . . . . . . . . . . $\underline{26}$

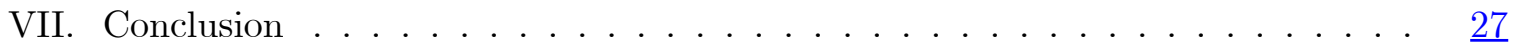

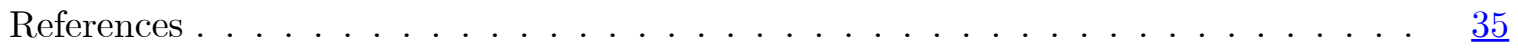

Figures

1. Savings, Investment and Current Account Balances: U.S. and the Rest of the

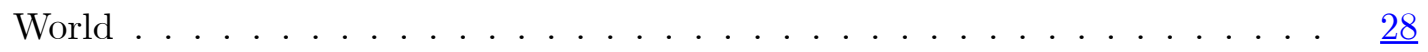

2. Real Interest Rates and EMBI Spreads . . . . . . . . . . . . . . . . . . $\underline{29}$

3. Sources of National Savings in the United States . . . . . . . . . . . . . $\underline{29}$

4. Flow Chart of the Model . . . . . . . . . . . . . . . . . . $\underline{30}$

5. Permanent Increase in Government Debt in OLG and REP - Part I . . . . . $\quad \underline{31}$

6. Permanent Increase in Government Debt in OLG and REP - Part II . . . . . . $\underline{32}$

7. Cuts in Government Investment and Consumption . . . . . . . . . . . . $\underline{33}$

8. Lower U.S. Rate of Time Preference and Higher RW Rate of Time Preference $\underline{34}$ 


\section{Introduction}

The short-term expansionary effects of fiscal deficits and the medium- and long-term crowding-out effects of the resulting increased government debt continue to be topics of considerable interest in both policymaking and academic circles. In an age of increasing macroeconomic interdependence across countries this interest is no longer exclusively motivated by the study of individual economies, but also by spillovers between multiple economies. ${ }^{1}$ Probably the most pressing example, and the subject of this paper, is the concern with U.S. fiscal deficits in the context of global current account imbalances. The question we ask, and attempt to answer with the help of a new non-Ricardian model, is whether the post-2001 deterioration in U.S. fiscal balances should be seen as a major contributing factor to the simultaneous further deterioration in U.S. current account balances. Or conversely, would a U.S. fiscal consolidation make a sizeable contribution to the resolution of global current account imbalances?

It is important to emphasize that U.S. fiscal policy has been only one of the drivers affecting the U.S. current account deficit, and that higher national savings rates in the rest of the world have probably been even more important. Figure 1 summarizes recent trends in savings and investment flows in the U.S. and the rest of the world. To understand the impact of world savings on world real interest rates, Figure 2 plots the short-term real interest rate for the U.S. and for a group of advanced economies excluding the U.S., as well as a measure of spreads for emerging-market economies. The first important observation is that over the last few years national savings have increased significantly in the rest of the world, accompanied by real interest rates that have trended down in all major regions of the world. This supports Bernanke's (2005) hypothesis that the world is experiencing a "savings glut", and that this has been responsible for a large part of the increase in the U.S. current account deficit. Due to many differences in individual countries' accounting conventions, it is difficult to consistently decompose national savings in the rest of the world into public and private savings. ${ }^{2}$ However, detailed fiscal data are available for the U.S., and are shown in Figure 3. These data suggest that since 2001 lower U.S. public savings have reduced national savings, which confirms that U.S. fiscal policy should be another candidate explanation for larger U.S. current account deficits.

Recent model-based estimates of the effects of U.S. fiscal deficits derived from the Federal Reserve Board's SIGMA model and the IMF's Global Economy Model (GEM) have attracted considerable attention in policymaking circles. ${ }^{3}$ The estimates from both of these institutions are based on a new generation of open economy monetary business cycle models with both nominal and real rigidities that are being deployed rapidly in central banks to replace the previous generation of models, which were not completely based on

\footnotetext{
${ }^{1}$ See, for example, Chinn (2005), Chinn and Ito (2005), Chinn and Lee (2005), Chinn and Steil (2006), Kopcke, Tootell and Triest (2004) and Truman (2006).

${ }^{2}$ In a recent paper Ferrero (2006) studies the effects of fiscal deficits in the U.S. relative to fiscal deficits outside the U.S. However, his fiscal data are restricted to the G6 and do not account for the recent increase in public savings in emerging Asia and the oil-exporting economies.

${ }^{3}$ For documentation on SIGMA see Erceg, Guerrieri and Gust, (2005a, b) and for GEM see Faruqee and others (2005). For applications to policymaking discussions see, for example, Bernanke (2005) and publications of the IMF's World Economic Outlook by Laxton and Milesi-Ferretti (2005) and Kumhof and Laxton (2006).
} 
microfoundations. ${ }^{4}$ Such models are well suited to address many monetary business cycle issues, but as argued in several important papers they face difficulties in adequately replicating the dynamic short-run effects of fiscal policy. ${ }^{5}$ More importantly for this paper, they have serious shortcomings when applied to the analysis of medium- and long-run fiscal issues such as the crowding-out effects of a permanent increase in public debt. ${ }^{6}$ Indeed, the prediction of both SIGMA and GEM is that U.S. fiscal deficits (and rest of the world fiscal surpluses) should have very small medium- and long-run effects on the current account balance and on world savings. It is important to emphasize that the results of the IMF analysis using GEM suggest larger and more sustained effects than the Federal Reserve Board's SIGMA model because the IMF's scenarios assume that the desired net foreign liability position will shift in response to higher levels of government debt - see Faruqee and others (2005).

In view of the importance of fiscal policy problems, the idea of bringing models with microfoundations as rigorous as those of open economy monetary business cycle models to the analysis of fiscal policy is very appealing. ${ }^{7}$ But to do so in a way that does not ignore the critical interactions between monetary and fiscal policies, the microfoundations of non-Ricardian household and firm behavior need to be built while maintaining the nominal and real rigidities of existing models.

The candidate non-Ricardian features known from the literature are overlapping generations models following Blanchard (1985) and Weil (1989) and infinite horizon models with a subset of liquidity constrained agents following Gali, López-Salido and Vallés (2007). Both model classes are capable of producing powerful short-run effects of fiscal policy. But only an overlapping generations structure produces medium- and long-run crowding out effects of government debt, and thereby endogenously determines net foreign liability positions as a function of government debt. Both of these effects are clearly critical to understanding the connection between fiscal and current account deficits that is the object of our study. An overlapping generations structure is therefore a key ingredient of this paper.

Bringing an overlapping generations setting into an open economy monetary business cycle model has been undertaken by Ghironi (2000a,b) and by Ganelli (2005). The former does not consider the effects of government debt, but shows that an overlapping generations structure following Blanchard (1985) and Weil (1989) ensures the existence of a well-defined steady state for net foreign liability positions (see also Buiter (1981)). Our model bears the closest resemblance to Ganelli (2005), which is the first attempt to analyze alternative fiscal policies in an open economy monetary business cycle model with finite lives. ${ }^{8}$ Our model adds to this several additional non-Ricardian features, a very general specification of preferences and technologies, and a number of nominal and real rigidities that are critical for the quantitative implications of our policy simulations. We show that the resulting model, which is built on complete optimizing foundations, nests the extreme Ricardian predictions of models such as SIGMA and GEM when the planning

\footnotetext{
${ }^{4}$ The related literature is very large. For some examples see Obstfeld and Rogoff $(1995,1996)$, Betts and Devereux (2001), Caselli(2001), Corsetti and Pesenti (2001), Ganelli (2003) and Laxton and Pesenti (2003).

${ }^{5}$ See Fatas and Mihov (2001), Blanchard and Perotti (2002), Gali, López-Salido and Vallés (2007).

${ }^{6}$ We think of the medium-run as encompassing the period between 5 and 25 years after a shock.

${ }^{7}$ See Ganelli and Lane (2002) for a discussion of the need to give a greater role to fiscal policy.

${ }^{8}$ Ganelli (2005) is in turn related to the work of Frenkel and Razin (1992).
} 
horizon is assumed to be infinite. But with finite horizons any change in taxes and debt has very significant real effects.

Our model has four non-Ricardian features. First, it features overlapping generations agents with finite economic lifetimes. This implies that today's agents discount future tax liabilities at a higher rate than the market real interest rate, because they attach a significant probability to not becoming responsible for them. Second, the model exhibits a stylized form of lifecycle income patterns whereby the average agent exhibits declining labor productivity throughout his lifetime. He therefore discounts future labor income tax liabilities at an even higher rate because he expects to be supplying less effective labor in the future. Third, the model features liquidity constrained (but nonetheless optimizing) agents who do not have access to financial markets to smooth consumption, so that they have to vary their consumption one-for-one with their after-tax income. And fourth, labor and consumption taxes are distortionary because labor effort and consumption respond to relative price movements that result directly from tax wedges.

Because one possible option for future fiscal consolidation consists of spending cuts rather than tax increases, we are also interested in a meaningful analysis of the spending component of fiscal policy. In this context, another important simplifying assumption of models such as SIGMA and GEM is that all government expenditures are wasted and do not add to productive capacity. This is clearly far too simple for a complete analysis of the potential costs that would be associated with future government spending cuts. We therefore also extend the standard model to allow for government investment in productive infrastructure.

As for preferences and technologies, a CRRA utility function allows us to highlight the critical role of the intertemporal elasticity of substitution in the propagation of fiscal shocks. ${ }^{9}$ Furthermore, the labor supply decision is endogenous. Another critical ingredient is endogenous capital formation, which provides an additional channel through which government debt crowds out economic activity. The specification of technology contains both traded and nontraded goods. Furthermore, the model economy features a full set of nominal and real rigidities typical of existing monetary business cycle models. Nominal rigidities go beyond the simple case of one-period price rigidities to allow for meaningful business cycle dynamics. They include multiple levels of sticky goods prices as well as sticky nominal wages. Real rigidities include habit persistence in consumption, investment adjustment costs, and import adjustment costs.

The combination of non-Ricardian features and rigidities allows us to introduce specifications of fiscal and monetary policy that interact with one another. A monetary policy reaction function familiar from state-of-the-art monetary theory stabilizes inflation and output, while fiscal policy stabilizes the government balance and therefore government debt. The short-run dynamics of the model are determined by the interaction of both of these policies, while the medium- and long-run dynamics depend only on fiscal policy.

\footnotetext{
${ }^{9}$ Previous overlapping generations models have often used log preferences to avoid complications during aggregation.
} 
The remainder of the paper is organized as follows. Section 2 summarizes the theoretical structure of the model, leaving some of the details to a Technical Appendix. Section 3 discusses a base-case calibration. Section 4 compares the model's short-run and long-run predictions for the consequences of higher government deficits and government debt with the predictions of a standard infinite horizon model augmented with liquidity-constrained consumers. We show that the two models behave very similarly in the very short run. But in the infinite horizon model the medium- and long-run effects of higher government debt are negligible, while in the finite horizon model, under plausible assumptions about agents' planning horizons, there is an economically highly significant link between higher government deficits and larger current account deficits, accompanied also by crowding out effects on physical capital stocks. Turning to scenarios of fiscal consolidation, Section 5 compares the implications of permanent cuts in government investment and government consumption, showing that the former permanently reduces output while the latter raises it. Section 6 studies the role of private sector savings behavior. We conclude that an increase in rest of the world savings is likely to be playing a key role, as it is consistent with not only U.S. current account deficits but also with the observed low world real interest rate. Section 7 concludes.

\section{The Model}

The world consists of 2 countries, the United States (U.S.) and the rest of the world (RW). The flow of goods and factors between the different domestic sectors, and between the two economies, is illustrated in Figure 4. When discussing the behavior of agents in one country alone we will not identify the country by additional notation. When the interaction between two countries is discussed we identify the U.S. by an asterisk.

Each country is populated by two types of households, both of which consume final retailed output and supply labor to unions. First, there are overlapping generations households $(O L G)$ with finite planning horizons as in Blanchard (1985), and exhibiting external habit persistence. In each period, $n^{*}\left(1-\psi^{*}\right)(1-\theta)$ and $n(1-\psi)(1-\theta)$ of such individuals are born in the U.S. and RW, respectively. Second, there are liquidity constrained households $(L I Q)$ who do not have access to financial markets, and who consequently are forced to consume their after tax income in every period. The number of such agents born in each period in the U.S. and in RW is $n^{*} \psi^{*}(1-\theta)$ and $n \psi(1-\theta)$. Each agent faces a constant probability of death $(1-\theta)$ in each period, which implies an average planning horizon of $1 /(1-\theta) .{ }^{10}$ This implies that the total number of agents in the U.S. and in RW is $n^{*}$ and $n$. In addition to the probability of death households also experience labor productivity that declines at a constant rate over their lifetimes. ${ }^{11}$ Lifecycle income adds another powerful channel through which fiscal policies have non-Ricardian effects. Households of both types are subject to a uniform labor income tax and a uniform consumption tax.

\footnotetext{
${ }^{10}$ In general we allow for the possibility that agents may be more myopic than what would be suggested by a planning horizon based on a biological probability of death.

${ }^{11}$ This stylized treatment of lifecycle income is made possible by the absence of explicit demographics in our model, which means that we only need the assumption of declining labor productivity to be correct for the average worker.
} 
Firms are managed in accordance with the preferences of their owners, myopic $O L G$ households, and they therefore also have finite planning horizons. Each country's primary production is carried out by manufacturers producing tradable and nontradable goods. Manufacturers buy investment goods from distributors and and labor from unions. Unions are subject to nominal wage rigidities and buy labor services from households. ${ }^{12}$

Manufacturers are subject to nominal rigidities in price setting as well as real rigidities in capital accumulation. Manufacturers' domestic sales go to domestic distributors. Their foreign sales go to intermediate goods import agents that are domestically owned but located in each export destination country. Import agents in turn sell their output to foreign distributors subject to nominal rigidities in foreign currency (pricing-to-market). Distributors first assemble manufactured nontradable and home and foreign tradable goods, where changes in the volume of imported inputs are subject to an adjustment cost. This private sector output is then combined with a publicly provided capital stock (infrastructure) as an essential further input. This capital stock is maintained through government investment expenditure that is financed by tax revenue. The combined domestic private and public sector output is combined with foreign final output to produce domestic final output. Foreign final output is purchased through final goods import agents. Domestic final output is sold to domestic consumption goods retailers, domestic manufacturing firms (in their role as investors), the domestic government, and to final goods import agents located in foreign economies. Distributors are subject to another layer of nominal rigidities in price setting. Retailers face real instead of nominal rigidities. While their output prices are flexible they find it costly to rapidly adjust their sales volume. This feature contributes to generating inertial consumption dynamics.

Asset markets are incomplete. There is complete home bias in government debt, which takes the form of nominally non-contingent one-period bonds denominated in domestic currency. The only assets traded internationally are nominally non-contingent one-period bonds denominated in the currency of the U.S. There is also complete home bias in ownership of domestic firms. In addition equity is not traded in domestic financial markets, instead households receive lump-sum dividend payments.

The world economy grows at the constant rate $g=T_{t} / T_{t-1}$, where $T_{t}$ is the level of labor augmenting world technology. The model's real variables, say $x_{t}$, therefore have to be rescaled by $T_{t}$, where we will use the notation $\check{x}_{t}=x_{t} / T_{t}$. The steady state of $\check{x}_{t}$ is denoted by $\bar{x}$. In our derivations per capita variables are only considered at the level of disaggregated households. All aggregate variables represent absolute rather than per capita quantities. This paper presents results for the perfect foresight case, but extensions to log-linear approximations are trivial, as explained in the Technical Appendix.

\footnotetext{
${ }^{12}$ Clearly "union" is only a convenient label. This sector was introduced because aggregation across generations would become impossible if nominal wage rigidities were faced by households themselves rather than unions. For similar reasons, capital accumulation takes place within manufacturers rather than households.
} 


\section{A. Households}

\section{Overlapping Generations Households}

We first describe the optimization problem of $O L G$ households. A representative member of this group and of age $a$ derives utility at time $t$ from consumption $c_{a, t}^{O L G}$ relative to the consumption habit $h_{a, t}^{O L G}$, leisure $\left(1-\ell_{a, t}^{O L G}\right)$ (where 1 is the time endowment), and real balances $\left(M_{a, t} / P_{t}^{R}\right)$ (where $P_{t}^{R}$ is the retail price index). The lifetime expected utility of a representative household of age $a$ at time $t$ has the form

$E_{t} \sum_{s=0}^{\infty}(\beta \theta)^{s}\left[\frac{1}{1-\gamma}\left(\left(\frac{c_{a+s, t+s}^{O L G}}{h_{a+s, t+s}^{O L G}}\right)^{\eta^{O L G}}\left(1-\ell_{a+s, t+s}^{O L G}\right)^{1-\eta^{O L G}}\right)^{1-\gamma}+\frac{u^{m}}{1-\gamma}\left(\frac{M_{a+s, t+s}}{P_{t+s}^{R}}\right)^{1-\gamma}\right]$

where $\beta$ is the discount factor, $\theta<1$ determines the degree of myopia, $\gamma>0$ is the coefficient of relative risk aversion, and $0<\eta^{O L G}<1$. As for money demand, in the following analysis we will only consider the case of the cashless limit advocated by Woodford (2003), where $u^{m} \longrightarrow 0$. The Technical Appendix discusses this. The consumption habit is given by lagged per capita consumption of $O L G$ households

$$
h_{a, t}^{O L G}=\left(\frac{c_{t-1}^{O L G}}{n(1-\psi)}\right)^{v}
$$

where $v$ parameterizes the degree of habit persistence. This is the external, "catching up with the Joneses" variety of habit persistence. Consumption $c_{a, t}^{O L G}$ is given by a CES aggregate over retailed consumption goods varieties $c_{a, t}^{O L G}(i)$, with elasticity of substitution $\sigma_{R}$ :

$$
c_{a, t}^{O L G}=\left(\int_{0}^{1}\left(c_{a, t}^{O L G}(i)\right)^{\frac{\sigma_{R}-1}{\sigma_{R}}} d i\right)^{\frac{\sigma_{R}}{\sigma_{R}-1}} .
$$

This gives rise to a demand for individual varieties

$$
c_{a, t}^{O L G}(i)=\left(\frac{P_{t}^{R}(i)}{P_{t}^{R}}\right)^{-\sigma_{R}} c_{a, t}^{O L G}
$$

where $P_{t}^{R}(i)$ is the retail price of variety $i$, and the aggregate retail price level $P_{t}^{R}$ is given by

$$
P_{t}^{R}=\left(\int_{0}^{1}\left(P_{t}^{R}(i)\right)^{1-\sigma_{R}} d i\right)^{\frac{1}{1-\sigma_{R}}}
$$

A household can hold domestic government bonds $B_{a, t}$ denominated in domestic currency, and foreign bonds denominated in the currency of the U.S. The nominal exchange rate vis-a-vis the U.S. is denoted by $\mathcal{E}_{t}$, and $\mathcal{E}_{t} F_{a, t}$ are nominal net foreign asset holdings in terms of domestic currency. In each case the time subscript $t$ denotes financial claims held from period $t$ to period $t+1$. Gross nominal interest rates on U.S. and RW currency denominated assets held from $t$ to $t+1$ are $i_{t}^{*}$ and $i_{t}$. Participation by households in financial markets requires that they enter into an insurance contract with companies that pay a premium of $\frac{(1-\theta)}{\theta}$ on a household's financial wealth for each period in which that 
household is alive, and that encash the household's entire financial wealth in the event of his death. ${ }^{13}$

Apart from returns on financial assets, households also receive labor income from unions and dividend income from firms. The productivity of an individual household's labor declines throughout his lifetime, with productivity $\Phi_{a, t}$ of age group $a$ given by

$$
\Phi_{a, t}=\Phi_{a}=\kappa \chi^{a},
$$

where $\chi<1$. The overall population's average productivity is assumed without loss of generality to be equal to one. Household pre-tax nominal labor income is therefore $W_{t} \Phi_{a, t} \ell_{a, t}^{O L G}$. Dividends are received in a lump-sum fashion from all firms in the nontradables $(N)$ and tradables $(T)$ manufacturing sectors, the distribution $(D)$, retail $(R)$ and import agent $(M)$ sectors, and from all unions $(U)$ in the labor market, with after-tax nominal dividends received from firm/union $i$ denoted by $D_{a, t}^{j}(i), j=N, T, D, R, U, M$. $O L G$ households are liable to pay lump-sum transfers $\tau_{T_{a, t}}^{O L G}$ to the government, which in turn redistributes them to the relatively less well off $L I Q$ agents. Household labor income is taxed at the rate $\tau_{L, t}$ and consumption is taxed at the rate $\tau_{c, t}$. It is assumed that retailers, due to adjustment costs, periodically offer incentives (or disincentives) that are incorporated into the effective retail purchase price $P_{t}^{R}$. The consumption tax $\tau_{c, t}$ is however assumed to be payable on the pre-incentive price $P_{t}$, which equals the price at which retailers purchase consumption goods from distributors. We choose the aggregate final goods price level $P_{t}$ (determined by distributors) as our numeraire.

The real wage is denoted by $w_{t}=W_{t} / P_{t}$, the nominal price, relative price and gross inflation rate of any good $x$ by $P_{t}^{x}, p_{t}^{x}=P_{t}^{x} / P_{t}$ and $\pi_{t}^{x}=P_{t}^{x} / P_{t-1}^{x}$, gross final goods inflation by $\pi_{t}=P_{t} / P_{t-1}$, and gross nominal exchange rate depreciation by $\varepsilon_{t}=\mathcal{E}_{t} / \mathcal{E}_{t-1} \cdot{ }^{14}$ The real exchange rate vis-a-vis the U.S. is $e_{t}=\left(\mathcal{E}_{t} P_{t}^{*}\right) / P_{t}$. We adopt the convention that each nominal asset is deflated by the final output price index of the currency of its denomination, so that real domestic bonds are $b_{t}=B_{t} / P_{t}$ and real internationally traded bonds are $f_{t}=F_{t} / P_{t}^{*}$. The real interest rate in terms of final output is $r_{t}=i_{t} / \pi_{t+1}$. The household's budget constraint in nominal terms is

$$
\begin{gathered}
P_{t}^{R} c_{a, t}^{O L G}+P_{t} c_{a, t}^{O L G} \tau_{c, t}+B_{a, t}+\mathcal{E}_{t} F_{a, t}=\frac{1}{\theta}\left[i_{t-1} B_{a-1, t-1}+i_{t-1}^{*} \mathcal{E}_{t} F_{a-1, t-1}\right] \\
+W_{t} \Phi_{a, t} \ell_{a, t}^{O L G}\left(1-\tau_{L, t}\right)+\sum_{j=N, T, D, R, U, M} \int_{0}^{1} D_{a, t}^{j}(i) d i-\tau_{T_{a, t}}^{O L G}
\end{gathered}
$$

The $O L G$ household maximizes (1) subject to (2), (3), (6) and (7). The derivation of the first-order conditions for each generation, and aggregation across generations, is discussed in the Technical Appendix. Aggregation takes account of the size of each age cohort at the time of birth, and of the remaining size of each generation. Using the example of $O L G$ households' consumption, we have

$$
c_{t}^{O L G}=n(1-\psi)(1-\theta) \Sigma_{a=0}^{\infty} \theta^{a} c_{a, t}^{O L G} .
$$

\footnotetext{
${ }^{13}$ The turnover in the population is assumed to be large enough that the income receipts of the insurance companies exactly equal their payouts.

${ }^{14}$ We adopt the convention throughout the paper that all nominal price level variables are written in upper case letters while all relative price variables are written in lower case letters.
} 
The first-order conditions for goods varieties demands and for the consumption/leisure choice are, after rescaling by technology, given by

$$
\begin{gathered}
\check{c}_{t}^{O L G}(i)=\left(\frac{P_{t}^{R}(i)}{P_{t}^{R}}\right)^{-\sigma_{R}} \check{c}_{t}^{O L G}, \\
\frac{\check{c}_{t}^{O L G}}{n(1-\psi)-\ell_{t}^{O L G}}=\frac{\eta^{O L G}}{1-\eta^{O L G}} \check{w}_{t} \frac{\left(1-\tau_{L, t}\right)}{\left(p_{t}^{R}+\tau_{c, t}\right)} .
\end{gathered}
$$

The arbitrage condition for foreign currency bonds (the uncovered interest parity relation) is

$$
i_{t}=i_{t}^{*} \varepsilon_{t+1} .
$$

We now discuss a key set of optimality conditions of the model. They express current aggregate consumption of $O L G$ households as a function of their real aggregate financial wealth $f w_{t}$ and human wealth $h w_{t}$, with the marginal propensity to consume of out of wealth given by $1 / \Theta_{t}$. Human wealth is in turn composed of $h w_{t}^{L}$, the expected present discounted value of households' time endowments evaluated at the after-tax real wage, and $h w_{t}^{K}$, the expected present discounted value of dividend income plus the expected present discounted value of lump-sum transfers to or from the government $\tau_{T_{t}}$. After rescaling by technology we have

$$
\check{c}_{t}^{O L G} \Theta_{t}=\check{f} w_{t}+\check{h} w_{t}
$$

where

$$
\begin{aligned}
& \Theta_{t}=\frac{p_{t}^{R}+\tau_{c, t}}{\eta^{O L G}}+\frac{\theta j_{t}}{r_{t}} \Theta_{t+1}, \\
& \check{f} w_{t}=\frac{1}{\pi_{t} g}\left[i_{t-1} \check{b}_{t-1}+i_{t-1}^{*} \varepsilon_{t} \check{f}_{t-1} e_{t-1}\right] \text {, } \\
& \check{h} w_{t}=\check{h} w_{t}^{L}+\check{h} w_{t}^{K}, \\
& \check{h} w_{t}^{L}=\left(n(1-\psi)\left(\check{w}_{t}\left(1-\tau_{L, t}\right)\right)\right)+\frac{\theta \chi g}{r_{t}} \check{h} w_{t+1}^{L} \text {, } \\
& \check{h}_{t}^{K}=\left(\check{d}_{t}^{N}+\check{d}_{t}^{T}+\check{d}_{t}^{D}+\check{d}_{t}^{R}+\check{d}_{t}^{U}+\check{d}_{t}^{M}-\check{\tau}_{T, t}\right)+\frac{\theta g}{r_{t}} \check{h}_{t+1}^{K} \text {, } \\
& j_{t}=\left(\beta \frac{i_{t}}{\pi_{t+1}}\right)^{\frac{1}{\gamma}}\left(\frac{p_{t}^{R}+\tau_{c, t}}{p_{t+1}^{R}+\tau_{c, t+1}}\right)^{\frac{1}{\gamma}}\left(\frac{\check{w}_{t+1} g\left(1-\tau_{L, t+1}\right)\left(p_{t}^{R}+\tau_{c, t}\right)}{\check{w}_{t}\left(1-\tau_{L, t}\right)\left(p_{t+1}^{R}+\tau_{c, t+1}\right)}\right)^{\left(1-\eta^{O L G}\right)\left(1-\frac{1}{\gamma}\right)} \\
& \left(\frac{\check{c}_{t}^{O L G} g}{\check{c}_{t-1}^{O L G}}\right)^{v \eta^{O L G}\left(1-\frac{1}{\gamma}\right)} \chi^{\left(1-\eta^{O L G}\right)\left(1-\frac{1}{\gamma}\right)} \text {. }
\end{aligned}
$$

The intuition of (12) - (18) is as follows. Financial wealth (14) is equal to the domestic government's and foreign households' current financial liabilities. For the government debt portion, the government services these liabilities through different forms of taxation, and these future taxes are reflected in the different components of human wealth (15) as well as in the marginal propensity to consume (13). But unlike the government, which is infinitely lived, an individual household factors in that he might not be alive by the time higher future tax payments fall due. Hence a household discounts future tax liabilities by a rate of at least $r_{t} / \theta$, which is higher than the market rate $r_{t}$, as reflected in the discount factors in (16), (17) and (13). The discount rate for the labor income component of 
human wealth is even higher at $r_{t} / \theta \chi$, due to the decline of labor incomes over individuals' lifetimes. The implication is that government debt is net wealth to the extent that households do not expect to become responsible for the taxes necessary to service that debt. The more myopic households are, the greater the portion of outstanding government debt that they consider to be net wealth.

A fiscal expansion through lower taxes represents a tilting of the tax payment profile from the near future to the more distant future, so as to effect an increase in the debt stock. The government has to respect its intertemporal budget constraint in effecting this tilting, and this means that the expected present discounted value of its future primary surpluses has to remain equal to the current debt $i_{t-1} b_{t-1} / \pi_{t}$ when future surpluses are discounted at the market interest rate $r_{t}$. But when individual households discount future taxes at a higher rate than the government, the same tilting of the tax profile represents an increase in human wealth because it decreases the value of future taxes for which the household expects to be responsible. For a given marginal propensity to consume, this increase in human wealth leads to an increase in consumption.

The marginal propensity to consume $1 / \Theta_{t}$ is, in the simplest case of logarithmic utility, exogenous labor supply and no consumption taxes, equal to $(1-\beta \theta)$. For the case of endogenous labor supply, household wealth can be used to either enjoy leisure or to generate purchasing power to buy goods. The main determinant of the split between consumption and leisure is the consumption share parameter $\eta^{O L G}$, which explains its presence in the marginal propensity to consume (13). While other forms of taxation affect the different components of wealth, the time profile of consumption taxes affects the marginal propensity to consume, increasing it with a balanced-budget shift of such taxes from the present to the future. The intertemporal elasticity of substitution $1 / \gamma$ is another key parameter for the marginal propensity to consume. As can be seen in (18) it determines among other things the responsiveness of consumption to changes in the real interest rate $r$. For the conventional assumption of $\gamma>1$, the income effect of an increase in $r$ is stronger than the substitution effect and increases the marginal propensity to consume, thereby partly offsetting the contractionary effects of a higher $r$ on human wealth $\check{h} w_{t}$. Expression (18) also reflects the effects of habit persistence.

In our policy simulations we will compare our model to an infinite horizon representative agent alternative that is identical in all but three respects. First, the parameters $\theta$ and $\chi$ are assumed to be equal to one. Second, in order to nevertheless generate similar non-Ricardian behavior in the short run, the model will be calibrated with a higher share of $L I Q$ households than the baseline model. As is well known, that type of model is unable to determine the steady state level of net foreign liabilities in linearized or perfect foresight environments, and it therefore requires a third specification change whereby positive deviations from a target net foreign liabilities to GDP ratio raise the external interest rate faced by the country. That model gives rise to an identical system of equations except for a (numerically small) modification of the uncovered interest rate parity condition, and more importantly to a replacement of the consumption system (12)-(18) with the equation

$$
\check{c}_{t+1}^{O L G}=\frac{j_{t}}{g} \check{c}_{t}^{O L G},
$$

where in equation (18) for $j_{t}$ we set $\chi=1$. 


\section{Liquidity Constrained Households}

The objective function of $L I Q$ households is assumed to be identical to that of $O L G$ households except for the absence of money. But their budget constraint is different in that these agents can consume at most their current income, which consists of their after tax wage income plus government transfers $\tau_{T_{a},}^{L I Q}$. LIQ agents are not to be confused with the "rule of thumb" agents found in the literature, because unlike the latter they do solve an intratemporal optimization problem for their consumption-leisure choice. The aggregated first-order conditions for this problem, after rescaling by technology and letting $\check{\tau}_{T, t}$ be the aggregate lump-sum transfer from $O L G$ to $L I Q$ agents, are

$$
\begin{gathered}
\check{c}_{t}^{L I Q}(i)=\left(\frac{P_{t}^{R}(i)}{P_{t}^{R}}\right)^{-\sigma_{R}} \check{c}_{t}^{L I Q}, \\
\check{c}_{t}^{L I Q}\left(p_{t}^{R}+\tau_{c, t}\right)=\check{w}_{t} \ell_{t}^{L I Q}\left(1-\tau_{L, t}\right)+\check{\tau}_{T, t}, \\
\frac{\check{c}_{t}^{L I Q}}{n \psi-\ell_{t}^{L I Q}}=\frac{\eta^{L I Q}}{1-\eta^{L I Q}} \check{w}_{t} \frac{\left(1-\tau_{L, t}\right)}{\left(p_{t}^{R}+\tau_{c, t}\right)} .
\end{gathered}
$$

\section{Aggregate Household Sector}

To obtain aggregate consumption demand and labor supply we simply add the respective quantities for $O L G$ and $L I Q$ households:

$$
\begin{aligned}
& \check{C}_{t}=\check{c}_{t}^{O L G}+\check{c}_{t}^{L I Q}, \\
& L_{t}=\ell_{t}^{O L G}+\ell_{t}^{L I Q} .
\end{aligned}
$$

\section{B. Firms and Unions}

In each sector there is a continuum of agents, indexed by $i \in[0,1]$, that are perfectly competitive in their input markets and monopolistically competitive in their output markets. Their optimization problem is subject to nominal rigidities for manufacturers, unions, import agents and distributors, and subject to real rigidities for retailers. Manufacturers and distributors face a fixed cost of production that is calibrated to make the steady state shares of labor and capital in GDP consistent with the data. Each sector pays out each period's net cash flow as dividends to $O L G$ households. It maximizes the present discounted value of these dividends. The discount rate it applies in this maximization includes the parameter $\theta$ so as to equate the discount factor of firms $\theta / r_{t}$ with the pricing kernel for nonfinancial income streams of their owners, myopic households, which equals $\beta \theta\left(\lambda_{a+1, t+1} / \lambda_{a, t}\right)$. This equality follows directly from $O L G$ households' Euler equation $\lambda_{a, t}=\beta\left(\lambda_{a+1, t+1} r_{t}\right)$. 


\section{Manufacturers}

There are two manufacturing sectors indexed by $J \in[N, T]$, and prices in these two sectors are indexed by $\tilde{J} \in[N, T H]$. Manufacturers' customers demand a CES aggregate of manufactured varieties, with elasticity of substitution $\sigma_{J}$. The aggregate demand for variety $i$ produced by sector $J$ can be derived by aggregating over all sources of demand. We have

$$
Z_{t}^{J}(i)=\left(\frac{P_{t}^{\tilde{J}}(i)}{P_{t}^{\tilde{J}}}\right)^{-\sigma_{J}} Z_{t}^{J}
$$

where $P_{t}^{\tilde{J}}$ is defined analogously to (5), and where $Z_{t}^{J}(i)$ and $Z_{t}^{J}$ remain to be specified by way of market clearing conditions. The technology of each manufacturing firm is given by a CES production function in capital $K_{t}^{J}(i)$ and union labor $U_{t}^{J}(i)$, with elasticity of substitution $\xi_{J}$ and labor augmenting technology $T_{t}$ :

$$
Z_{t}^{J}(i)=F\left(K_{t}^{J}(i), U_{t}^{J}(i)\right)=\left(\left(1-\alpha_{J}^{U}\right)^{\frac{1}{\xi_{J}}}\left(K_{t}^{J}(i)\right)^{\frac{\xi_{J}-1}{\xi_{J}}}+\left(\alpha_{J}^{U}\right)^{\frac{1}{\xi_{J}}}\left(T_{t} U_{t}^{J}(i)\right)^{\frac{\xi_{J}-1}{\xi_{J}}}\right)^{\frac{\xi_{J}}{\xi_{J}-1}} .
$$

Manufacturing firms are subject to inflation adjustment costs $G_{P, t}^{J}(i)$. Following Ireland (2001) and Laxton and Pesenti (2003), these are quadratic in changes in the rate of inflation rather than in price levels, which helps to generate realistic inflation dynamics:

$$
G_{P, t}^{J}(i)=\frac{\phi_{P \tilde{J}}}{2} Z_{t}^{J}\left(\frac{\frac{P_{t}^{\tilde{J}}(i)}{P_{t-1}^{J}(i)}}{\frac{P_{t-1}^{\tilde{J}}}{P_{t-2}^{\tilde{J}}}}-1\right)^{2} .
$$

Capital accumulation is subject to quadratic adjustment costs $G_{I, t}(i)$ in gross investment $I_{t}^{J}(i)$ :

$$
G_{I, t}^{J}(i)=\frac{\phi_{I}}{2} K_{t}^{J}(i)\left(\frac{I_{t}^{J}(i)}{K_{t}^{J}(i)}-\frac{I_{t-1}^{J}}{K_{t-1}^{J}}\right)^{2}
$$

The law of motion of capital is described by

$$
K_{t+1}^{J}(i)=(1-\delta) K_{t}^{J}(i)+I_{t}^{J}(i),
$$

where $\delta$ represents the depreciation rate of capital. Dividends $D_{t}^{J}(i)$ equal nominal revenue $P_{t}^{\tilde{J}}(i) Z_{t}^{J}(i)$ minus nominal cash outflows. The latter include the wage bill $V_{t} U_{t}^{J}(i)$, where $V_{t}$ is the aggregate wage rate charged by unions, investment $P_{t} I_{t}^{J}(i)$, investment adjustment costs $P_{t} G_{I, t}(i)$, a fixed cost $P_{t}^{\tilde{J}} T_{t} \omega^{J}$ and price adjustment costs $P_{t}^{\tilde{J}} G_{P, t}^{J}(i)$. The fixed resource cost arises as long as the firm chooses to produce positive output. Net output in sector $J$ is therefore equal to $\max \left(0, Z_{t}^{J}(i)-T_{t} \omega^{J}\right)$. The optimization problem of each manufacturing firm is given by

$$
\begin{gathered}
\operatorname{Max} \\
\left\{P_{t+s}^{\tilde{J}}(i), U_{t+s}^{J}(i), I_{t+s}^{J}(i), K_{t+s+1}^{J}(i)\right\}_{s=0}^{\infty} \\
\Sigma_{s=0}^{\infty} \tilde{R}_{t, s} D_{t+s}^{J}(i), \\
\tilde{R}_{t, s}=\prod_{l=1}^{s} \frac{\theta}{i_{t+l-1}} \text { for } s>0(=1 \text { for } s=0), \\
D_{t}^{J}(i)=P_{t}^{\tilde{J}}(i) Z_{t}^{J}(i)-V_{t} U_{t}^{J}(i)-P_{t} I_{t}^{J}(i)-P_{t} G_{I, t}^{J}(i)-P_{t}^{\tilde{J}} G_{P, t}^{J}(i)-P_{t}^{\tilde{J}} T_{t} \omega^{J},
\end{gathered}
$$


and subject to (25)-(29). The first-order conditions for this problem are derived in the Technical Appendix. Apart from standard conditions for optimal choices of labor, investment and capital they include a Phillips curve equation for sectorial inflation $\pi_{t}^{\tilde{J}}$. We report it here partly for reference purposes, as it is identical in form to all other Phillips curves in the model. Letting $\lambda_{t}^{J}$ be the real marginal cost of sector $J$ output, we have

$$
\begin{aligned}
& {\left[\frac{\sigma_{J}}{\sigma_{J}-1} \frac{\lambda_{t}^{J}}{p_{t}^{\tilde{J}}}-1\right]=\frac{\phi_{P J}}{\sigma_{J}-1}\left(\frac{\pi_{t}^{\tilde{J}}}{\pi_{t-1}^{\tilde{J}}}\right)\left(\frac{\pi_{t}^{\tilde{J}}}{\pi_{t-1}^{\tilde{J}}}-1\right)} \\
& -\frac{\theta g}{r_{t}} \frac{\phi_{P} \tilde{J}}{\sigma_{J}-1} \frac{p_{t+1}^{\tilde{J}}}{p_{t}^{\tilde{J}}} \frac{\check{Z}_{t+1}^{J}}{\check{Z}_{t}^{J}}\left(\frac{\pi_{t+1}^{\tilde{J}}}{\pi_{t}^{\tilde{J}}}\right)\left(\frac{\pi_{t+1}^{\tilde{J}}}{\pi_{t}^{\tilde{J}}}-1\right) .
\end{aligned}
$$

\section{Unions}

Manufacturers demand a CES aggregate of labor varieties from unions, with elasticity of substitution $\sigma_{U}$. The aggregate demand for labor variety $i$ is therefore

$$
U_{t}(i)=\left(\frac{V_{t}(i)}{V_{t}}\right)^{-\sigma_{U}} U_{t}
$$

where $V_{t}$ is defined similarly to (5), and where $U_{t}$ is aggregate labor demand by all manufacturing firms. Nominal wage rigidities in this sector take the same functional form $G_{P, t}^{U}(i)$ as in (27). The optimization problem of a union consists of maximizing the present discounted value of nominal wages paid by firms $V_{t}(i) U_{t}(i)$ minus nominal wages paid out to workers $W_{t} U_{t}(i)$, minus nominal wage inflation adjustment $\operatorname{costs} P_{t} G_{P, t}^{U}(i)$. The first-order condition is a Phillips curve for wage inflation $\pi_{t}^{U}$ similar to (33).

\section{Import Agents}

The U.S. owns continua of intermediate and final goods import agents located in RW (and vice versa), and indexed by $J \in[T, D]$. Distributors demand a CES aggregate of varieties $Y_{t}^{J M}(i)$ from import agents, with elasticity of substitution $\sigma_{J M}$. The aggregate demand for variety $i$ is

$$
Y_{t}^{J M}(i)=\left(\frac{P_{t}^{J M}(i)}{P_{t}^{J M}}\right)^{-\sigma_{J M}} Y_{t}^{J M} .
$$

where $P_{t}^{J M}$ is defined similarly to (5), and where $Y_{t}^{J M}$ is aggregate import demand by all RW distributors in sector $J$. Nominal price rigidities for import agents take the same functional form $G_{P, t}^{J M}(i)$ as in (27). We denote the price of imported inputs at the border by $P_{t}^{M, c i f}$, the cif (cost, insurance, freight) import price. By purchasing power parity this satisfies

$$
p_{t}^{J M, c i f}=p_{t}^{J H^{*}} e_{t} \quad, \quad p_{t}^{J M, c i f^{*}}=\frac{p_{t}^{J H}}{e_{t}} .
$$

The optimization problem consists of maximizing the present discounted value of nominal revenue $P_{t}^{J M}(i) Y_{t}^{J M}(i)$ minus nominal costs of inputs $P_{t}^{J M, c i f} Y_{t}^{J M}(i)$, minus nominal inflation adjustment costs $P_{t} G_{P, t}^{J M}(i)$. The first-order condition is a Phillips curve for import price inflation $\pi_{t}^{J M}$ similar to (33). 


\section{Distributors}

This sector produces final output. Distributors' customers demand a CES aggregate of distributed varieties, with elasticity of substitution $\sigma_{D}$. The aggregate demand for variety $i$ is

$$
\mathcal{D}_{t}(i)=\left(\frac{P_{t}(i)}{P_{t}}\right)^{-\sigma_{D}} \mathcal{D}_{t}
$$

where the numeraire price index $P_{t}$ is defined similarly to (5), and where $\mathcal{D}_{t}(i)$ and $\mathcal{D}_{t}$ remain to be specified by way of market clearing conditions. We divide our description of the technology of distributors into a number of stages. In the first stage a tradables composite $Y_{t}^{T}(i)$ is produced by combining foreign tradables $Y_{t}^{T F}(i)$ with domestic tradables $Y_{t}^{T H}(i)$, subject to an adjustment cost that makes rapid changes in the share of foreign tradables costly. ${ }^{15}$ In the second stage a tradables-nontradables composite $Y_{t}^{A}(i)$ is produced. In the third stage this composite is in turn combined with a publicly provided stock of capital $K_{t}^{G}$ to produce $Y_{t}^{D H}$. And in the fourth stage, similar to the first stage, the private-public composite is combined with foreign final output, again subject to an import adjustment cost, to produce domestic final output $Y_{t}$. We have the following set of nested production functions:

$$
\begin{gathered}
Y_{t}^{T}(i)=\left(\left(\alpha_{T H}\right)^{\frac{1}{\xi_{T}}}\left(Y_{t}^{T H}(i)\right)^{\frac{\xi_{T}-1}{\xi_{T}}}+\left(1-\alpha_{T H}\right)^{\frac{1}{\xi_{T}}}\left(Y_{t}^{T F}(i)\left(1-G_{F, t}^{T}(i)\right)\right)^{\frac{\xi_{T}-1}{\xi_{T}}}\right)^{\frac{\xi_{T}}{\xi_{T}-1}}, \\
Y_{t}^{A}(i)=\left(\left(1-\alpha_{N}\right)^{\frac{1}{\xi_{A}}}\left(Y_{t}^{T}(i)\right)^{\frac{\xi_{A}-1}{\xi_{A}}}+\left(\alpha_{N}\right)^{\frac{1}{\xi_{A}}}\left(Y_{t}^{N}(i)\right)^{\frac{\xi_{A}-1}{\xi_{A}}}\right)^{\frac{\xi_{A}}{\xi_{A}-1}}, \\
Y_{t}^{D H}(i)=Y_{t}^{A}(i)\left(K_{t}^{G}\right)^{\alpha_{G}} \mathcal{S}, \\
Y_{t}(i)=\left(\left(\alpha_{D H}\right)^{\frac{1}{\xi_{D}}}\left(Y_{t}^{D H}(i)\right)^{\frac{\xi_{D}-1}{\xi_{D}}}+\left(1-\alpha_{D H}\right)^{\frac{1}{\xi_{D}}}\left(Y_{t}^{D F}(i)\left(1-G_{F, t}^{D}(i)\right)\right)^{\frac{\xi_{D}-1}{\xi_{D}}}\right)^{\frac{\xi_{D}}{\xi_{D}-1}} .
\end{gathered}
$$

The import adjustment cost term for intermediates is given by

$$
G_{F, t}^{T}(i)=\frac{\phi_{F T}}{2} \frac{\left(\mathcal{R}_{t}^{T}-1\right)^{2}}{1+\left(\mathcal{R}_{t}^{T}-1\right)^{2}}, \mathcal{R}_{t}^{T}=\frac{\frac{Y_{t}^{T F}(i)}{Y_{t}^{T}(i)}}{\frac{Y_{t-1}^{T F}}{Y_{t-1}^{T}}}
$$

and similarly for imports of final goods. The stock of public infrastructure $K_{t}^{G}$ is identical for all firms and provided free of charge to the end user (but not of course to the taxpayer). It enters in a similar fashion to the level of technology, but with decreasing returns to public capital. The advantage of this formulation is that it retains constant returns to scale at the level of each firm. The term $\mathcal{S}$ is a technology scale factor that is used to normalize the relative size of each economy to correspond to its relative weight $n /\left(n+n^{*}\right)$. Nominal price rigidities in this sector take the same functional form $G_{P, t}^{D}(i)$ as

\footnotetext{
${ }^{15}$ This assumption has become widely used. It addresses a key concern in open economy DSGE models, namely the potential for an excessive short-term responsiveness of international trade to real exchange rate movements.
} 
in (27). The profit maximization problem of distributors consists of maximizing the present discounted value of nominal revenue $P_{t}(i) Y_{t}(i)$ minus nominal costs of production $P_{t}^{T H} Y_{t}^{T H}(i)+P_{t}^{T F} Y_{t}^{T F}(i)+P_{t}^{N} Y_{t}^{N}(i)+P_{t}^{D F} Y_{t}^{D F}(i)$, a fixed cost $P_{t} T_{t} \omega^{D}$, and inflation adjustment costs $P_{t} G_{P, t}^{D}(i)$. First-order conditions for this problem consist of a Phillips curve for final goods inflation $\pi_{t}$ similar to (33) and a number of input demands listed in the Technical Appendix.

\section{Retailers}

Household demand for the output varieties $C_{t}(i)$ supplied by retailers follows directly from (9) and (20) as

$$
C_{t}(i)=\left(\frac{P_{t}^{R}(i)}{P_{t}^{R}}\right)^{-\sigma_{R}} C_{t}
$$

Retailers face quantity adjustment costs that take the form ${ }^{16}$

$$
G_{Y, t}^{R}(i)=\frac{\phi_{C}}{2} C_{t}\left(\frac{\left(C_{t}(i) / g\right)-C_{t-1}(i)}{C_{t-1}(i)}\right)^{2} .
$$

The optimization problem of retailers consists of maximizing the present discounted value of nominal revenue $P_{t}^{R}(i) C_{t}(i)$ minus nominal costs of inputs $P_{t} C_{t}(i)$, minus nominal quantity adjustment costs $P_{t} G_{Y, t}^{R}(i)$. The first order condition for the retailer's problem has the form

$$
\begin{aligned}
& {\left[\frac{\sigma_{R}-1}{\sigma_{R}} p_{t}^{R}-1\right]=\phi_{C}\left(\frac{\check{C}_{t}-\check{C}_{t-1}}{\check{C}_{t-1}}\right) \frac{\check{C}_{t}}{\check{C}_{t-1}}} \\
& -\frac{\theta g}{r_{t}} \phi_{C}\left(\frac{\check{C}_{t+1}-\check{C}_{t}}{\check{C}_{t}}\right)\left(\frac{\check{C}_{t+1}}{\check{C}_{t}}\right)^{2} .
\end{aligned}
$$

\section{Government}

\section{Fiscal Policy}

Fiscal policy consists of a specification of taxes $\tau_{L, t}$ and $\tau_{c, t}$, transfers $\tau_{T, t}$, and government spending for consumption and investment purposes $G_{t}^{c o n s}$ and $G_{t}^{i n v}$. The government's policy rule for transfers from $O L G$ agents to $L I Q$ agents specifies that dividends of the retail and union sector are redistributed in proportion to $L I Q$ agents' share in consumption and labor supply, while the redistributed share of dividends in the four remaining sectors is $\iota \leq \psi$. We therefore have the following rule:

$$
\check{\tau}_{T, t}=\iota\left(\check{d}_{t}^{N}+\check{d}_{t}^{T}+\check{d}_{t}^{D}+\check{d}_{t}^{M}\right)+\frac{\check{c}_{t}^{L I Q}}{\check{C}_{t}} \check{d}_{t}^{R}+\frac{\ell_{t}^{L I Q}}{L_{t}} \check{d}_{t}^{U} .
$$

\footnotetext{
${ }^{16}$ The presence of the growth term in (44) ensures that adjustment costs are zero along the balanced growth path.
} 
Government consumption spending is exogenous and unproductive. Government investment spending on the other hand augments the stock of publicly provided infrastructure capital $K_{t}^{G}$, the evolution of which is given by

$$
\check{K}_{t+1}^{G} g_{t+1}=\left(1-\delta_{G}\right) \check{K}_{t}^{G}+\check{G}_{t}^{i n v}
$$

The government issues nominally non-contingent one-period debt $B_{t}$ at the gross nominal interest rate $i_{t}$. Letting $\breve{b}_{t}=B_{t} / P_{t} T_{t}$, the real government budget constraint therefore takes the form

$$
\begin{gathered}
\check{b}_{t}=\frac{i_{t-1}}{\pi_{t} g} \check{b}_{t-1}-\check{s}_{t}, \\
\check{s}_{t}=\tau_{L, t} \check{w}_{t} L_{t}+\tau_{c, t} \check{C}_{t}-\check{G}_{t}^{c o n s}-\check{G}_{t}^{i n v},
\end{gathered}
$$

where $\check{s}_{t}$ is the primary surplus. Fiscal policy targets a possibly time-varying government surplus to GDP ratio $\mathfrak{r}_{t}$, which automatically ensures a non-explosive government debt to GDP ratio:

$$
\frac{\check{s}_{t}-\frac{\left(i_{t-1}-1\right) \check{b}_{t-1}}{\pi_{t} g}}{g \check{d} p_{t}}=\frac{-\check{b}_{t}+\frac{\check{b}_{t-1}}{\pi_{t} g}}{g \check{d} p_{t}}=\mathfrak{r}_{t} .
$$

The rule can be implemented by adjusting one of the tax rates to generate sufficient revenue, or by reducing one of the expenditure items.

\section{Monetary Policy}

Monetary policy uses an interest rate rule to stabilize inflation and output growth. The rule is similar to the class of rules suggested by Orphanides (2003), with one important exception. This is that in our non-Ricardian model there is no unchanging steady state real interest rate. The term proxying the steady state nominal interest rate $r_{t}^{\text {smooth }} \pi_{t+1}$ therefore includes a moving average of past and future real interest rates that tracks the evolution of the equilibrium real interest rate over time:

$$
\begin{gathered}
i_{t}=\left(i_{t-1}\right)^{\mu_{i}}\left(r_{t}^{s m o o t h} \pi_{t+1}\right)^{1-\mu_{i}}\left(\frac{\pi_{t+1}}{\bar{\pi}}\right)^{\left(1-\mu_{i}\right) \mu_{\pi}}\left(\frac{g \check{d} p_{t}}{g \check{d} p_{t-1}}\right)^{\left(1-\mu_{i}\right) \mu_{y g r}}, \\
r_{t}^{\text {smooth }}=\left(r_{t-1} r_{t} r_{t+1}\right)^{\frac{1}{3}} .
\end{gathered}
$$

We define a government policy to be a sequence of policy instruments $\left\{G_{s}^{i n v}, G_{s}^{\text {cons }}, \tau_{L, s}\right.$, $\left.\tau_{c, s}, i_{s}\right\}_{s=t}^{\infty}$ such that (46), (48), (49), (50), (51) and (52) hold at all times.

\section{Equilibrium and Balance of Payments}

A perfect foresight equilibrium is an allocation, a price system and a government policy such that $O L G$ and $L I Q$ households maximize lifetime utility, manufacturers, unions, import agents, distributors and retailers maximize the present discounted value of their cash flows, and the following market clearing conditions for labor, nontradables, tradables and final output hold: ${ }^{17}$

\footnotetext{
${ }^{17}$ Only the market clearing conditions for RW are listed. U.S. conditions are symmetric.
} 


$$
\begin{gathered}
U_{t}=U_{t}^{N}+U_{t}^{H}=L_{t}=\ell_{t}^{O L G}+\ell_{t}^{L I Q}, \\
\check{Z}_{t}^{N}=\check{Y}_{t}^{N}+\omega^{N}+\check{G}_{P, t}^{N}, \\
\check{Z}_{t}^{T}=\check{Y}_{t}^{T H}+\check{Y}_{t}^{T F^{*}}+\omega^{T}+\check{G}_{P, t}^{T H}, \\
\check{Y}_{t}=\check{C}_{t}+\check{I}_{t}^{N}+\check{I}_{t}^{H}+\check{G}_{t}^{i n v}+\check{G}_{t}^{c o n s}+\check{Y}_{t}^{D F^{*}}+\omega^{D}+\check{G}_{I, t}^{N}+\check{G}_{I, t}^{T}+\check{G}_{P, t}^{D}+\check{G}_{P, t}^{U}+\check{G}_{P, t}^{M}+\check{G}_{Y, t}^{R} .
\end{gathered}
$$

Furthermore, the net foreign asset evolution is given by ${ }^{18}$

$$
e_{t} \check{f}_{t}=\frac{i_{t-1}^{*} \varepsilon_{t}}{\pi_{t} g} e_{t-1} \check{f}_{t-1}+p_{t}^{T H} \check{Y}_{t}^{T F^{*}}+\check{d}_{t}^{T M}-p_{t}^{T F} \check{Y}_{t}^{T F}+\check{Y}_{t}^{D F^{*}}+\check{d}_{t}^{D M}-p_{t}^{D F} \check{Y}_{t}^{D F}
$$

The market clearing condition for international bonds is

$$
\check{f}_{t}+\check{f}_{t}^{*}=0 \text {. }
$$

Finally, the level of GDP is given by the following expression:

$$
g \check{d} p_{t}=\check{C}_{t}+\check{I}_{t}^{N}+\check{I}_{t}^{H}+\check{G}_{t}^{i n v}+\check{G}_{t}^{c o n s}+p_{t}^{T H} \check{Y}_{t}^{T F^{*}}+\check{d}_{t}^{T M}+\check{Y}_{t}^{D F^{*}}+\check{d}_{t}^{D M}-p_{t}^{T F} \check{Y}_{t}^{T F}-p_{t}^{D F} \check{Y}_{t}^{D F} .
$$

\section{Calibration}

We calibrate the model for a two-country world representing the U.S. and RW. Because the critical fiscal effects stressed in this model are of a medium- to long-term nature, we work with an annual version of the model.

We begin with the parameters and features that are assumed to be asymmetric between the U.S. and RW. First, the denomination of international bonds is in U.S. currency. The U.S. is calibrated to represent 25 percent of world GDP, and to have long-run or steady state government debt to GDP and net foreign liabilities (NFL) to GDP ratios of 60 percent and 55 percent. RW therefore has a net foreign assets to GDP ratio of 18.3 percent, and is assumed to have a government debt to GDP ratio of 30 percent. The assumed share $\psi$ of liquidity constrained agents in the population is 33 percent for the U.S. and 50 percent in RW. The assumption for the U.S. is significantly lower than the 50 percent assumed by Erceg, Guerrieri and Gust (2005b), but may still be on the high side given the empirical evidence presented in Weber (2002). We calibrate the trade share parameters $\alpha_{T H}, \alpha_{D H}, \alpha_{T H}^{*}$ and $\alpha_{D H}^{*}$ to produce U.S. ratios to GDP of intermediate and final goods imports and of intermediate goods exports of 6 percent, which is in line with historical averages, and to normalize the initial steady state final output based real exchange rate $e$ to 1 . Given the size difference between U.S. and RW this does of course produce correspondingly lower import and export shares for RW. Finally we assume an asymmetry in price setting behavior, in that exporters are subject to nominal rigidities in the U.S. market while U.S. exporters do not price to the RW market. All other structural parameters and macroeconomic ratios are assumed to be equal in both economies.

\footnotetext{
${ }^{18}$ Note that export earnings include the markup profits $\check{d}_{t}^{T M}$ and $\breve{d}_{t}^{D M}$ earned by domestically owned import agents.
} 
We fix the steady state world real growth rate at $1.5 \%$ per annum or $\bar{g}=1.015$, and the steady state inflation rate in each country at $2 \%$ per annum or $\bar{\pi}=1.02$. Trend nominal exchange rate depreciation is therefore zero. Given that there are no long-run trends in relative productivity and therefore in real exchange rates, the long-run real interest rate is equalized across countries, and we assume a value of $2 \%$ per annum or $\bar{r}=1.02$. We find the values of $\beta$ and $\beta^{*}$ that are consistent with these and the following assumptions.

The parameters $\theta$ and $\chi$ are critical for the non-Ricardian behavior of the model. We assume an average remaining time at work of 20 years, which corresponds to $\chi=0.95$. The degree of myopia is given by the planning horizon $1 /(1-\theta)$, which we assume to equal 10 years, implying $\theta=0.9{ }^{19}$ The main criterion used in choosing these parameters is the empirical evidence for the effect of government debt on real interest rates. Our model is calibrated so that a one percentage point increase in the government debt to GDP ratio in the U.S. leads to an approximately four basis points increase in the U.S. (and world) real interest rate. This value is towards the lower end of the estimates of Engen and Hubbard (2004) and Laubach (2003). Household preferences are further characterized by an intertemporal elasticity of substitution of 0.25 , or $\gamma=4$, and by habit persistence $v=0.4$. The Frisch elasticity of labor supply depends on the steady state value of labor supply among both $O L G$ and $L I Q$ households, which is in turn determined by the leisure share parameters $\eta^{O L G}$ and $\eta^{L I Q}$. We adjust these parameters to obtain a Frisch elasticity of 0.5. Pencavel (1986) reports that most microeconomic estimates of the Frisch elasticity are between 0 and 0.45 , and our calibration is at the upper end of that range, in line with much of the business cycle literature. ${ }^{20}$

We now turn to the calibration of technologies. The elasticities of substitution between capital and labor in both tradables and nontradables, $\xi_{Z N}$ and $\xi_{Z T}$, are assumed to be equal to one. The elasticities of substitution between domestic and foreign traded intermediates and final goods, $\xi_{T}$ and $\xi_{D}$, which correspond to the long-run price elasticities of demand for imports, are assumed to be equal to 1.5 as in Erceg, Guerrieri and Gust (2005b). We also explore the sensitivity of our results to lower values for these elasticities, as their macroeconomic estimates are typically closer to one, see Hooper and Marquez (1995) and Hooper, Johnson and Marquez (2000). Finally, the elasticity of substitution between tradables and nontradables, $\xi_{A}$, is assumed to equal 0.5 , based on the evidence cited in Mendoza (2005).

The real adjustment cost parameters are chosen to yield aggregate dynamics consistent with the empirical evidence. ${ }^{21}$ We set investment adjustment costs to $\phi_{I}=10$. Trade and consumption adjustment costs $\phi_{F T}, \phi_{F D}$ and $\phi_{C}$ are equal to 5. The trade adjustment costs ensure that our impulse responses roughly match the short-run behavior of exports and imports in Erceg, Guerrieri and Gust (2005b), who choose a different functional form

\footnotetext{
${ }^{19}$ Based on U.S. annual data starting in 1955 Bayoumi and Sgherri (2006) decisively reject the infinite horizon model and estimate a planning horizon that is significantly shorter than 10 years. However, in their study it was difficult to separately identify the share of liquidity-constrained consumers and the length of the planning horizon.

${ }^{20}$ As discussed by Chang and Kim (2005), a very low Frisch elasticity makes it difficult to explain cyclical fluctuations in hours worked, and they present a heterogenous agent model in which aggregate labor supply is considerably more elastic than individual labor supply.

${ }^{21}$ A fully satisfactory calibration of these parameters will ultimately require the model to be estimated. Given its size this is a formidable challenge, but given its expected wide application to policy analysis inside the IMF this is nevertheless an important part of our research agenda.
} 
for adjustment costs.

As for price setting in different sectors, the degree of market power is reflected in the markup of price over marginal cost. We assume that this markup is equal to 20 percent in the two manufacturing sectors and in the labor market. This is a typical assumption in the monetary business cycle literature. For the distribution and retail sectors we assume smaller markups of 5 percent, and for import agents of 2.5 percent. The key parameter for nominal rigidities is the inflation adjustment cost. Here we choose values that yield plausible dynamics over the first two to three years following a shock. Specifically, for all sectors except import agents in RW (where adjustment costs are zero) we set this parameter equal to 10 .

A number of share and other parameters is calibrated by reference to long-run values for the shares of different expenditure and income categories in GDP. The manufacturing labor share parameters $\alpha_{N}^{U}$ and $\alpha_{T}^{U}$ are set to ensure a labor income share of 64 percent in aggregate and in each sector. The nontradables share parameter $\alpha_{N}$ is adjusted to ensure a nontradables share in GDP of 50 percent. The steady state shares of investment spending and government spending in GDP are calibrated based on historical averages to equal 16 percent and 18 percent, respectively. Given the assumptions about real interest rates and net foreign liabilities, this implies consumption to GDP ratios of 65.7 percent in the U.S. and 66.1 percent in RW.

Calibrating the depreciation rate of private capital would ordinarily present a problem given that we have already fixed the two capital income shares and the investment to GDP ratio. The only three free parameters available for to fix these four values would typically be $\alpha_{N}^{U}, \alpha_{T}^{U}$ and $\delta$. But in our model the income of capital consists not only of the return to capital in manufacturing, but also of economic profits due to market power in multiple sectors. We have introduced fixed costs in manufacturing and distribution that partly or wholly eliminate these profits. The percentage of steady state economic profits that is eliminated by fixed costs can therefore be specified as a fourth free parameter. This allows us to calibrate the annual depreciation rate of private capital at the conventional 10 percent while maintaining the investment to GDP ratio and capital income shares stated above.

The most challenging aspect of the model calibration is the specification of public capital stock accumulation and of its productivity, because our specification is to our knowledge new in macroeconomic studies. ${ }^{22}$ First, the U.S. national accounts data allow us to decompose public spending into spending on infrastructure investment and spending on all other items. As a share of GDP, the former represents 3 percent and the latter 15 percent. We use this to determine the ratio between the steady state values of productive and unproductive government spending, but it should be clear that other decompositions would be very justifiable. Most troubling is that education and health spending are thereby classified as completely unproductive. Kamps (2004) presents evidence for the depreciation rate of public capital of 4 percent per annum. We therefore set $\delta_{G}=0.04$. Together with a 3 percent productive spending to GDP ratio and a 1.5 percent per annum real growth rate this implies a public capital stock to GDP ratio of 54.5 percent, which is consistent with Kamps' (2004) evidence of around 50 percent. The productivity of public

\footnotetext{
${ }^{22}$ An exception is the recent working paper by Straub and Tchakarov (2006).
} 
capital is determined by the parameter $\alpha_{G}$. Ligthart and Suárez (2005) present a meta analysis that evaluates a large number of studies on the elasticity of aggregate output with respect to public capital. Their best estimate puts this elasticity at 0.14 . This is considerably below the highly controversial estimates of Aschauer $(1989,1998)$, but it is nevertheless very significant. We adjust the value of $\alpha_{G}$ to obtain a long-run elasticity of GDP with respect to $K^{G}$ of 0.14 .

For the monetary policy rules in each country we assume relatively little interest rate smoothing, $\mu_{i}=0.25$, given that this is an annual model. The coefficient on inflation is assumed to be $\mu_{\pi}=0.6$, and the coefficient on output growth is $\mu_{y g r}=0.25$.

Finally, in the alternative representative agent model we raise the share of U.S. liquidity constrained agents $\psi^{*}$ from 33 to 50 percent to compensate for the fact that the remaining agents now exhibit Ricardian behavior. Following standard practice in calibrating this type of model to the U.S. economy, we set the parameter that governs the speed with which NFL returns to its long run value as small as possible so that we can generate as much current account persistence as possible without creating dynamic instabilities in the model's properties.

\section{Implications of U.S. Government Deficits}

In this section we employ our finite horizon model, referred to as FH below, to analyze the implications of permanent changes in U.S. government deficits due to tax policy. We do so while comparing its short- and especially medium- and long-run predictions to those of the main alternative framework that has recently been used to study fiscal issues, the infinite horizon representative agent model augmented by liquidity-constrained consumers, referred to as REP. The latter approach has been very useful for studying a number of interesting questions, but we are concerned with its application to problems involving highly persistent changes in government debt.

\section{A. Useful Steady-State Relationships}

To better understand the current account implications of changes in public savings rates, it is useful to start by recalling the long-run relationship between the stock of net foreign liabilities and the current account deficit. Along the balanced growth path all nominal variables must grow at their steady-state nominal growth rate, which under our calibration is 3.53 percent ( 2 percent inflation plus 1.5 percent productivity growth), or $g \pi=1.0353 .^{23}$ The nominal current account deficit is equal to the change in the level of NFL:

$$
C D E F_{t}=N F L_{t}-N F L_{t-1} \text {. }
$$

\footnotetext{
${ }^{23}$ We assume that population will eventually stabilize. With declining fertility rates most long-term population projections usually assume that over the next several decades population growth will gradually decline to zero. In this paper we ignore the transitional effects of population growth, but we are in the processs of generalizing the model to account for population growth in either the steady state or along a transition path to a steady state with zero population growth.
} 
Along the balanced growth path we have $N F L_{t-1}=N F L_{t} / g \pi$. Dividing both sides of (60) by nominal GDP, we therefore obtain a very simple expression that links long-run current account deficit ratios and NFL ratios:

$$
\frac{C D E F}{G D P}=\frac{g \pi-1}{g \pi} \frac{N F L}{G D P}=0.0341 \frac{N F L}{G D P} .
$$

A 10 percentage point increase in the NFL ratio is therefore associated in the very long run with a 0.341 percentage point increase in the current account deficit ratio. Along the transition path to the higher NFL position the current account deficit generally changes by larger amounts over some period of time until the NFL ratio reaches its new long-run value.

Since the nominal government deficit is equal to the change in nominal government debt, a relationship similar to (61) exists between the government deficit ratio $G D E F / G D P$ and the stock of government debt $G D E B T / G D P$ :

$$
\frac{G D E F}{G D P}=\frac{g \pi-1}{g \pi} \frac{G D E B T}{G D P}=0.0341 \frac{G D E B T}{G D P} .
$$

The key difference between FH models and REP models is that the latter assume that those consumers who are not liquidity constrained always save sufficiently to pay the future tax burden associated with higher levels of government debt, while in FH models all consumers are disconnected from future generations and do not save sufficiently to pay the additional tax burden. Instead their investment in government debt crowds out their investment in physical capital and, crucially for this paper, in foreign assets. In practical terms this means that in REP models the long-run NFL position can, and in fact must, be specified independently of the level of government debt, while in $\mathrm{FH}$ models it depends on several fundamental factors that affect savings and investment, including the level of government debt. ${ }^{24}$ Specifically, in FH models there is a long-term positive causal relationship between government debt and net foreign liabilities. Given the two relationships above linking flows and stocks, it is clear that FH models also imply that there is a long-term causal relationship between government savings and the current account deficit. On the other hand, given the strong long-run assumption of REP models, fiscal deficits can have short-run effects on the current account deficit, but by design they are much smaller, and they must die out over time.

Another important difference between FH and REP models concerns the long-run equilibrium real interest rate. In the REP model this rate is tied down by the rate of time preference and productivity growth, while in the FH model it is related to the same fundamental parameters that affect the savings-investment relationship.

\section{B. The Quantitative Predictions of the Two Models}

To study the predictions of the two models we consider a fiscal expansion that permanently reduces the government savings ratio by 0.5 percentage points. To accelerate

\footnotetext{
${ }^{24}$ Other key drivers of savings and investment dynamics include the rate of time preference and the length of planning horizons, but it is also affected by assumptions that affect the sensitivity of savings and investment to real interest rates, including the intertemporal elasticity of substitution, the share of liquidity constrained consumers, and parameters of the production function.
} 
the increase in government debt we assume that the fiscal expansion is much larger in the short run ( -2.5 for the first 2 years and then gradually falling to -0.5 by the 5 th year of the simulation). In both models we assume that the reduction in government savings is a result of lower tax rates on labor income, which has important expansionary effects on consumption and aggregate demand in the short run. Figures 5 and 6 illustrate. ${ }^{25}$ The solid/dashed lines report the responses of the FH/REP models.

Both models predict that a reduction in government savings will result in a gradual increase in the government debt to GDP ratio of 14.7 percentage points $(\triangle(G D E F / G D P) / 0.0341)$. The labor tax rate declines by about 5 percentage points in the first 2 years and then starts to rise gradually to pay the additional interest payments on the rising stock of government debt. In the long run the labor tax rate is about 1.5 percentage points higher in the FH model and about 0.5 percentage points higher in the REP model. This difference reflects a permanent increase in the real interest rate and strong crowding-out effects in the $\mathrm{FH}$ model ${ }^{26}$ that require larger tax hikes over time to pay the higher interest burden.

The non-Ricardian nature of the FH model implies a short-run consumption boom in the first few years following the shock, because consumers do not save sufficiently to service the higher tax burden that will be imposed on future generations. The private sector savings rate therefore rises by less than the decline in the government savings rate. The REP model initially behaves similarly, because the share of liquidity-constrained individuals has been increased from $33 \%$ in the $\mathrm{FH}$ model to $50 \%$ in the REP model. Because the initial effects of the shock fall on consumption it is not surprising that the short-run effects on real GDP as well as its major components (investment, exports and imports) are very similar across the two models - see the left hand column of panels in Figure 6. However, the similarities in the predictions of the models end here. Looking beyond the short run, there are very large differences.

The behavior of the portion of agents that is not liquidity constrained drives the mediumto long-run dynamics of the two models. In the REP model their savings rate rises to completely offset the lower government savings rate after about 5 years. As there is no further crowding out after that point, the NFL position never changes by very much. But after the same 5 years the FH model predicts a drop in the private savings rate below its initial value, because of the wealth effects associated with higher tax rates that are necessary to finance higher debt obligations. Therefore, to equilibrate world savings and investment, real interest rates rise by about 40 basis points. This has a secondary effect on savings, as the income effect of higher real interest rates (recall our assumption that $\gamma>1$ ) supports consumption, or lowers savings. But in the U.S. a large gap remains between domestic savings and domestic investment at the higher real interest rate, leading to a permanently higher current account deficit and NFL position. Furthermore, the higher real interest rate results in long-term crowding-out effects on investment, consumption and GDP. As long-run real interest rates are equalized internationally, there will also be large spillover effects to the rest of the world.

\footnotetext{
${ }^{25}$ The left column of panels in Figure 5 shows the sources and uses of savings (public savings, private savings, investment and the current account deficit) while the right column of panels shows how these flows cumulate into government debt, financial wealth (government debt minus NFL), physical capital and NFL.

${ }^{26}$ The small but highly persistent accumulation of foreign liabilities in the REP model is entirely due to our assumption of a very small NFL adjustment cost parameter.
} 
The real exchange rate experiences a short-run appreciation in the $\mathrm{FH}$ model, consistent with the trade deficits that follow the reduction in national savings in the U.S. Over time it depreciates as the trade balance improves to finance the larger interest obligations associated with a higher stock of net foreign liabilities. The real exchange rate moves by significantly less in the REP model, and again this simply reflects the assumption that fiscal deficits have only very small effects on the current account over the medium and long term.

A number of the quantitative results from the FH model are sensitive to parameter values and other assumptions. First, the particular magnitude of the exchange rate response depends critically on the elasticity of substitution between imported goods and domestically produced tradables, which has been assumed to be 1.5 in the base-case calibration. Lower estimates of this elasticity require much larger short-run and long-run changes in the real exchange rate to generate the profile for trade volumes that is consistent with savings and investment dynamics. Second, the short-run response of real GDP may seem small and inconsistent with the effects estimated in historical episodes when monetary policy accommodated shocks to aggregate demand. It is important to understand that the monetary policy rule has been designed to keep inflation close to the target, so that the short-run expansionary effects of any positive aggregate demand shock are constrained by a rise in the real interest rate. Obviously, a policy that accommodated the expansion in demand by delaying hikes in nominal interest rates would generate a much larger short-run multiplier. For example, holding the short-term nominal interest rate fixed for the first 2 years of the simulation approximately doubles the short-run effects on GDP. Lastly, the magnitude of the crowding-out effects depends on a number of key assumptions. When the planning horizon is lengthened considerably ${ }^{27}$ the results of the model tend to mimic the Ricardian predictions of the REP model. In addition, for a given planning horizon, the magnitude of crowding-out effects on investment depends critically on how sensitive consumption is to real interest rates, as low degrees of interest rate sensitivity ${ }^{28}$ require larger changes in real interest rates to equilibrate world savings and investment. By contrast, the medium and long-term predictions of REP models for net foreign liabilities and real interest rates are far less sensitive to parameter assumptions since the basic long-term predictions are fixed by the assumption that net foreign liabilities positions and world real interest rates are independent of government debt. In our view this inability of REP models to account for any long-term effects of changes in government debt represents an obvious weakness that suggests caution in using them for fiscal experiments that involve such changes.

The preceding analysis suggests that fiscal deficits may have contributed to the further deterioration of U.S. current account deficits since 2000, and that given the long time lags involved in the build-up of larger government debt and NFL positions the main current account effects of these fiscal policies may still be to come. These same time lags also imply that any empirical investigation of the fiscal deficit-current account nexus may be very challenging. Looking forward, the same analysis can of course be used to suggest that an improvement in U.S. fiscal deficits should be part of a policy package that aims to raise national savings in the U.S. to help resolve global current account imbalances. Such fiscal

\footnotetext{
${ }^{27}$ Even for a 20 -year planning horizon the results are much closer to the 10-year planning horizon case than to the REP case.

${ }^{28}$ One possible reason is a low intertemporal elasticity of substitution.
} 
deficit improvements could take the form of higher taxes, but also of lower government spending. The consequences of the latter are dealt with in the next section. However, many commentators argue that the relative sizes of U.S. fiscal and current account deficits strongly suggest that this can only be part of the solution. The remainder requires either policy measures in the rest of the world, or adjustments in U.S. or rest of the world private sector behavior that may be difficult to accomplish through policy measures. Section 6 therefore explores the role of private sector savings behavior in bringing about global current account imbalances.

\section{Implications of Government Spending Cuts}

To the extent that government spending cuts are considered as part of a fiscal consolidation package, there is a risk that pressure to cut expenditures in all categories may result in a decline in productive government investment that could reduce the capacity of the private sector to produce output. It is to analyze this possibility that we have extended the basic FH model to allow for productive government investment. In Figure 7, the solid lines report the results of a permanent 10 percent reduction in government investment and the dashed lines report the results of a 10 percent reduction in government consumption. For both of these shocks we hold the government balance fixed by computing the implied profile of labor tax rates, so that we can see the pure effects of expenditure cuts without confusing them with effects due to changes in public sector savings rates.

When the cut in expenditures falls on government investment the model predicts a long-run decline in real GDP in the U.S. of about 1.4 percent, which is consistent with the empirical evidence discussed earlier. In the short run, the reduction in government investment reduces aggregate demand, principally because the crowding in of private consumption is limited by the negative effects of lower public investment on lifetime household wealth. Lower demand results in a decline in real interest rates, which works towards stimulating consumption and investment. However, over time as the lower level of government investment reduces the public capital stock, the supply-side effects start to dominate these short-run demand effects resulting in significant declines in private sector investment and consumption. In this case a reduction in supply to RW eventually results in higher imports, lower exports and an appreciation in the real exchange rate. The short-term and medium-term spillover effects on GDP in RW are positive.

The effects of a cut in government consumption have the opposite effects on GDP over the medium- and long-run. In this case, less government spending in the U.S. simply frees up resources for private sector consumption and investment. Investment declines in the short run as the boom in consumption results in higher interest rates. Part of the increase in GDP represents an increase in supply to RW (higher exports) and causes a depreciation in the real exchange rate. 


\section{Implications of Private Sector Savings Behavior}

FH models produce well-defined steady states where countries can be net debtors or creditors depending on the savings rates not only of the public sector but also of the private sector. Figure 8 presents two simulation experiments where the U.S. NFL position increases due to private sector savings behavior. One experiment (solid lines) considers a permanent one percentage point reduction in the U.S. rate of time preference that reduces U.S. private sector savings. The other experiment (dashed lines) considers a permanent one percentage point increase in the RW rate of time preference that raises RW private sector savings.

The negative shock to U.S. private sector savings results in a reduction in world savings, permanently higher real interest rates and a decline in output and consumption in both the U.S. and RW. The medium- and long-run effects are broadly similar to the effects of lower public sector savings discussed above.

The positive shock to RW savings results in a lower level of consumption in RW that crowds in investment and expands production. Over time consumption in RW rises, but it lags the increases in production, and this persistent rise in savings results in a 100 basis points reduction in real interest rates in both the U.S. and RW. This results in a consumption boom in the U.S. and eventually higher levels of GDP as the lower real interest rate stimulates investment. In the short run U.S. GDP declines as monetary policy is assumed to resist inflationary pressures, but just as was the case with the fiscal multipliers discussed in Section 4.2, a policy that delayed hikes in nominal interest rates would result in lower real interest rates in the short run and an expansion in GDP. The middle right panel of Figure 8 shows the path for the NFL position in the U.S., which declines initially but then shows a steady rise that stabilizes at a new higher steady-state value that is almost 10 percentage points higher, more than in the previous case because RW represents a larger share of world output and savings. The current account deteriorates by around 0.35 percentage points in the long run, and by significantly more in the short run. In this case there is a sharp U.S. real exchange rate appreciation, consistent with the profile of trade deficits that is generated by savings and investment dynamics.

Higher RW savings is the more interesting of the two cases considered in Figure 8, because it is consistent not only with an elevated U.S. NFL position but also with the observation of low world real interest rates over the last few years. It suggests that the major driving forces behind large U.S. current account deficits have not only been low U.S. private and public sector savings rates, but also factors that have increased the gap between savings rates and investment in RW. In our example we model this simply as an increase in private sector savings and abstract from changes in public sector savings and in perceived investment opportunities. We recognize that a complete analysis would consider all of these, but the implications for the U.S. are very similar in each case, as the transmission channel is always through the world supply of savings and the world real interest rate. ${ }^{29,30}$

\footnotetext{
${ }^{29}$ As discussed in the Introduction, a significant part of the increase in RW savings has been due to public rather than private sector savings. The analysis of Section 4.2, with opposite signs, applies to this case.

${ }^{30}$ Shifts in asset preferences or shifts in the perceived attractiveness of investment opportunities may have been important factors for determining recent movements in current account balances, but they are unlikely in our view to be the whole story given the degree of persistence in the U.S. NFL position.
} 
Although we have not yet performed a detailed accounting for the shocks that have been driving both real interest rates and the U.S. NFL position, these scenarios show that the FH model may well be able to account for the recent combination of low real world interest rates and a rising U.S. NFL position that would be difficult to account for in REP models that tie the NFL position down with arbitrary assumptions about its steady-state value, and that fix the long-run real interest rate by reference to the rate of time preference and the growth rate.

\section{Conclusion}

This paper has developed an open economy business cycle model suitable for the joint analysis of fiscal and monetary policies. The model combines the rigorous foundations of recent analytical frameworks developed for short-run monetary policy analysis with a finite horizon model that can be used to study the medium- and longer term effects of fiscal policy.

We use the model to analyze the potential effects of a permanent increase in U.S. government deficits and debt. We find that our framework gives rise to virtually identical short-run dynamics as a representative agent model with liquidity constrained consumers. But the medium- to long-run predictions are entirely different. While over that horizon higher government deficits have virtually no effect in representative agent models, in the finite horizon model they have a strong negative effect on the current account and on private capital accumulation. Conversely, fiscal consolidation can therefore make a substantial contribution to improving current account imbalances.

An additional strength of the model is its ability to analyze the consequences of cuts in productive government investment. Looking forward this feature will be very useful for a detailed study of alternative strategies for fiscal consolidation that require careful consideration of the trade-off between short-term demand management and longer-term supply repercussions.

To obtain a more complete perspective on the potential causes of U.S. current account deficits, the paper also analyzes the role of changes in private sector savings behavior. Specifically, we study the effects of lower U.S. private sector savings rates and higher private sector savings rates in the rest of the world. We conclude that higher rest of the world savings rates (not only private but also public) must have played an important role in recent years, as they are consistent not only with the existing pattern of current account imbalances but also with low world real interest rates. A reasonable interpretation of recent events is that this effect has been strong enough to ensure that none of the negative effects of U.S. fiscal policies analyzed in Section 4 has as yet materialized, except of course for even larger current account imbalances.

There are a number of worthwhile extensions in progress. First, it will be useful to extend the model to a multi-country setting to provide a more elaborate and detailed accounting for the causes and consequences of the recent behavior of private and public sector savings rates in both the U.S. and rest of the world. Second, we will develop a linearized version of the model that can be taken to the data and estimated with Bayesian methods so that we can account for a much larger set of shocks that are relevant for a more complete analysis of the role of both monetary and fiscal policies. 
Figure 1: Savings, Investment and Current Account Balances: U.S. and the Rest of the World
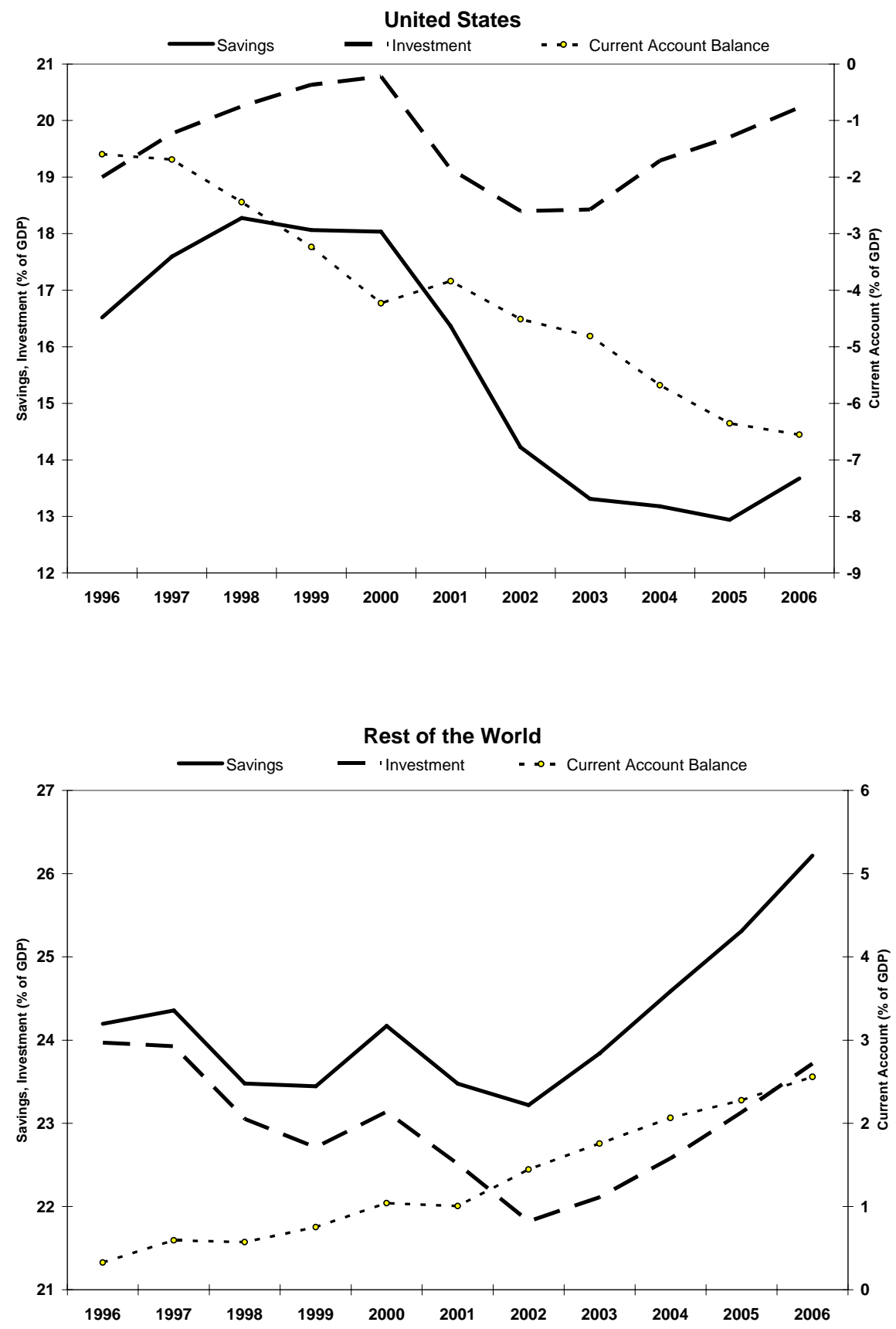
Figure 2: Real Interest Rates and EMBI Spreads

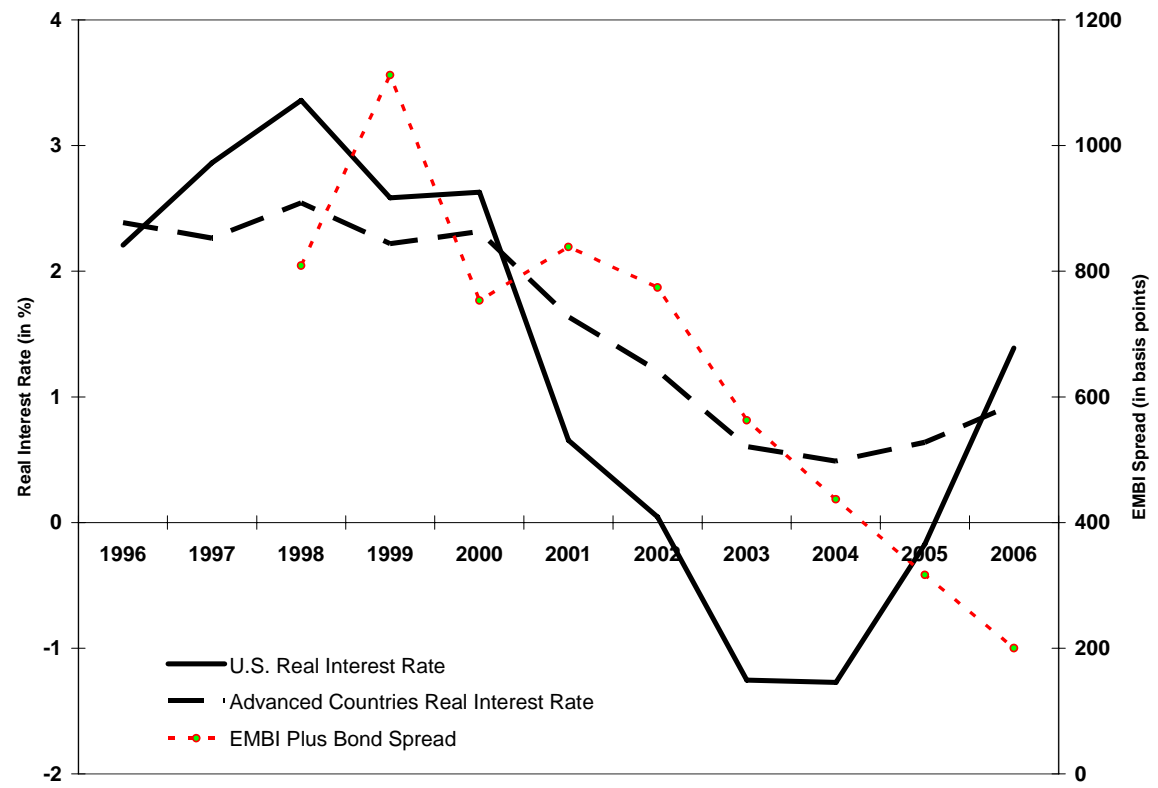

Figure 3: Sources of National Savings in the United States

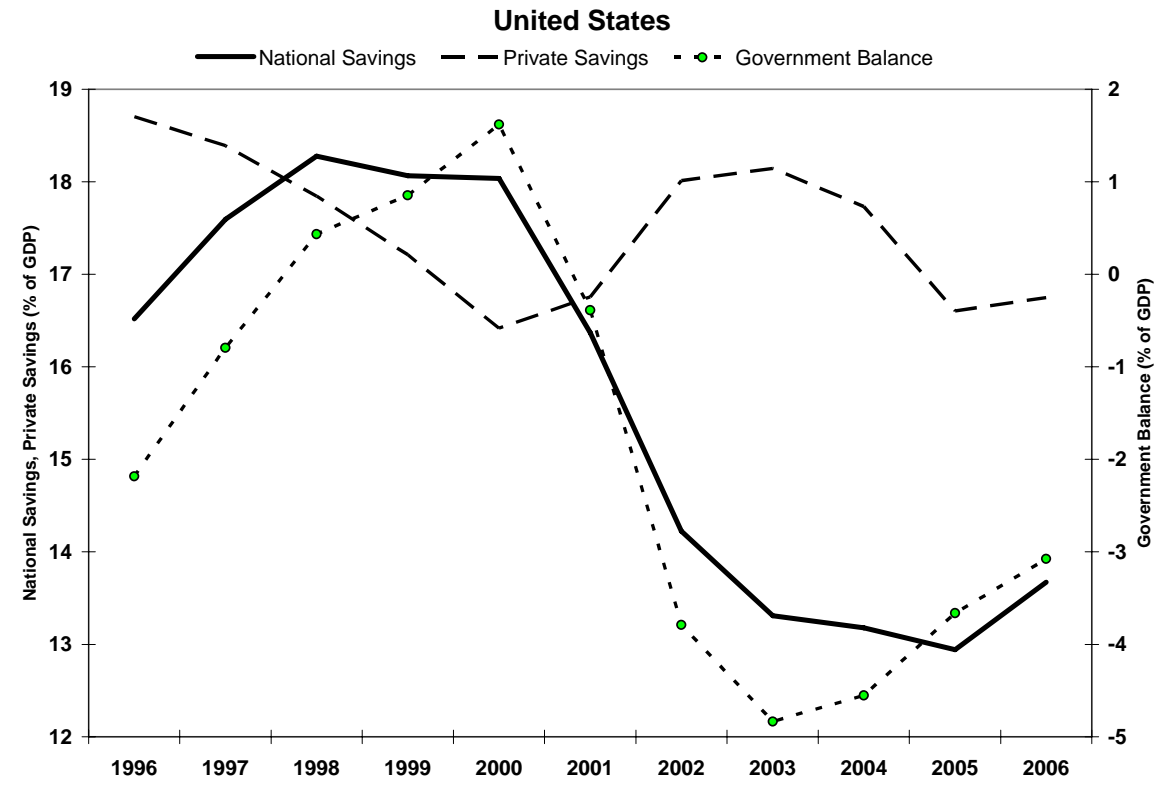


Figure 4: Flow Chart of the Model

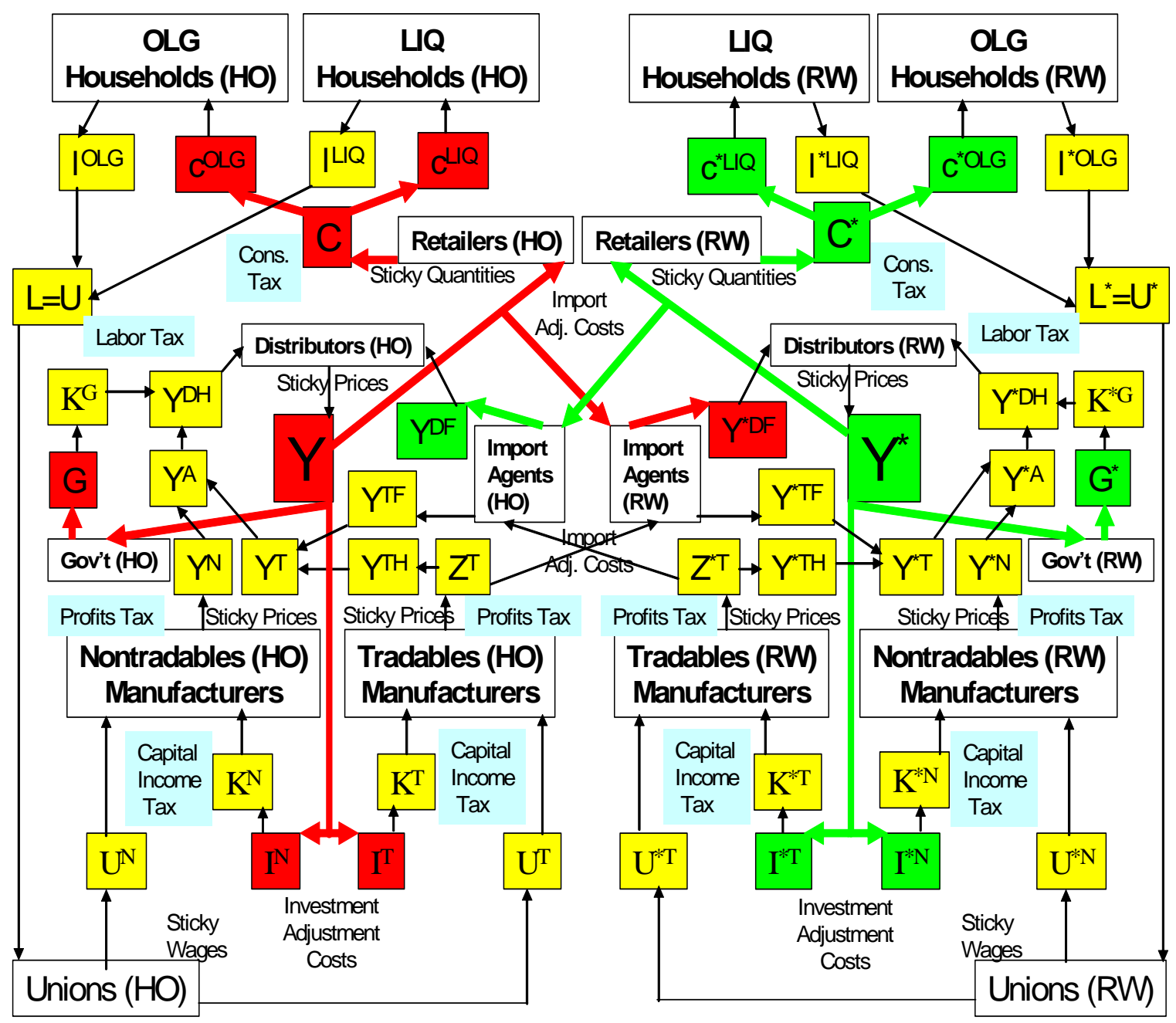


Figure 5: Permanent Increase in Government Debt in OLG and REP - Part I

U.S. Labor Tax Rate

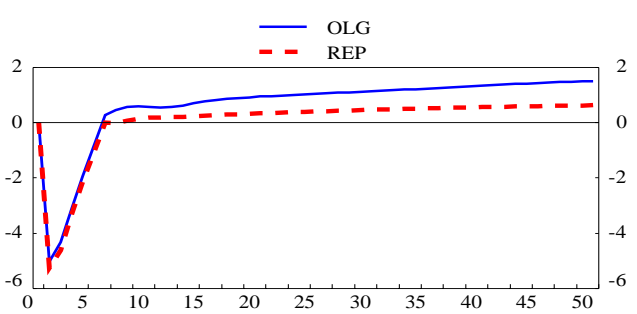

U.S. Government Savings Ratio

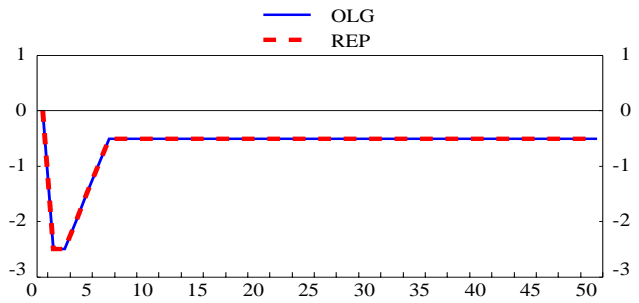

U.S. Private Savings Ratio

$\begin{array}{ll}- & \text { OLG } \\ -\mathbf{z} & \text { REP }\end{array}$

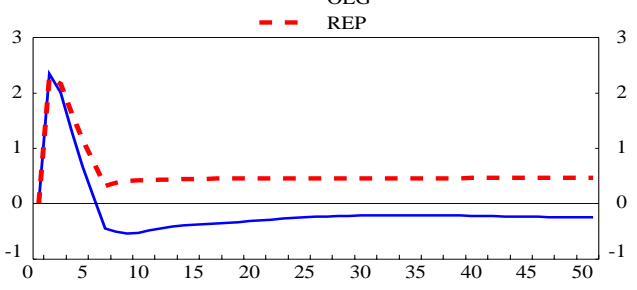

U.S. Investment Ratio

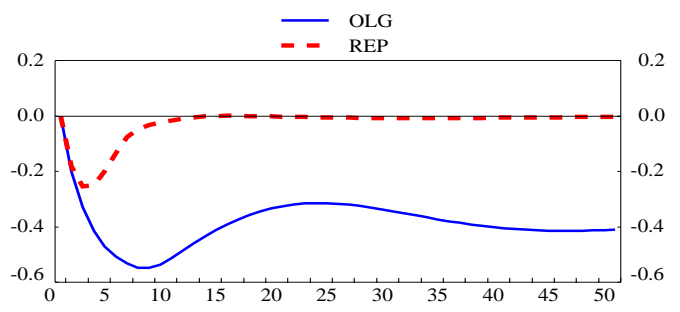

U.S. Current Account Deficit Ratio

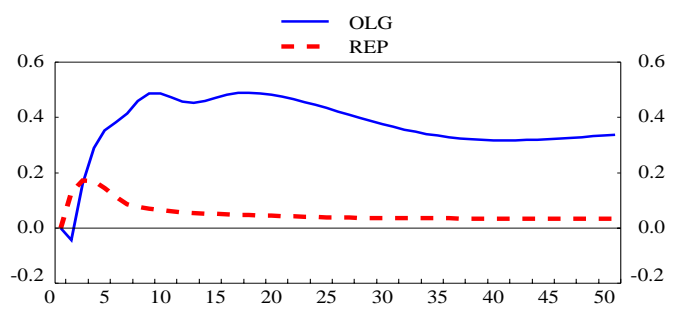

U.S. Real Interest Rate

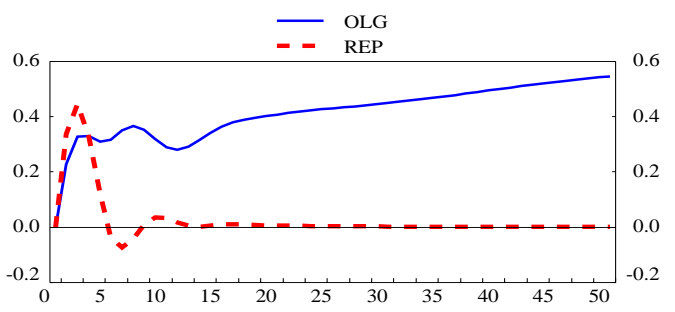

U.S. Government Debt Ratio

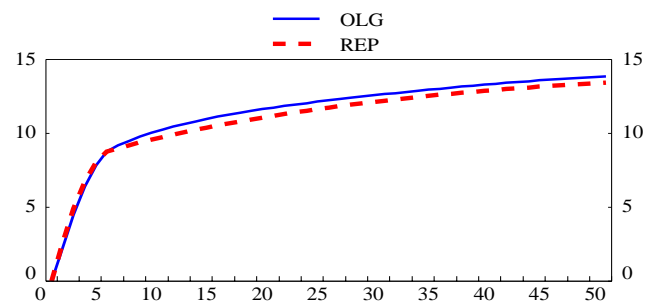

U.S. Financial Wealth Ratio

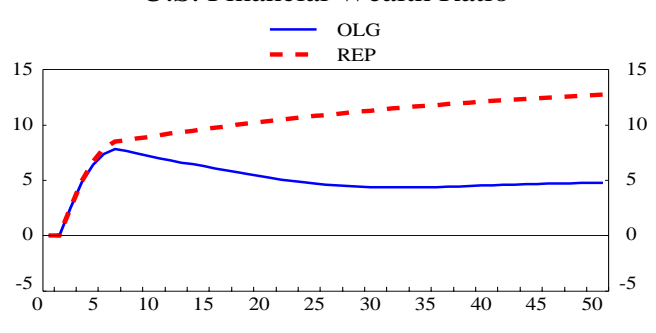

U.S. Real Capital Ratio

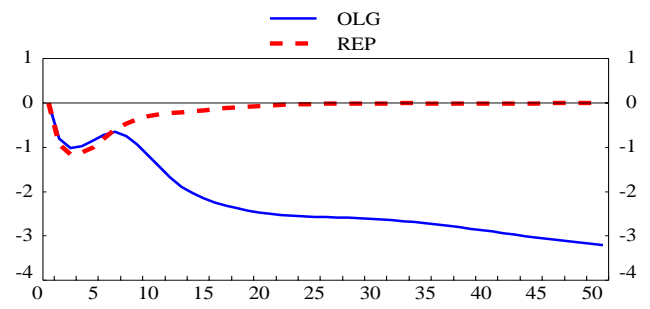

U.S. Net Foreign Liabilities Ratio

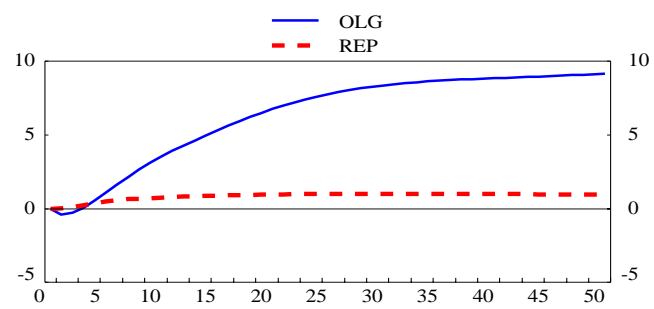


Figure 6: Permanent Increase in Government Debt in OLG and REP - Part II
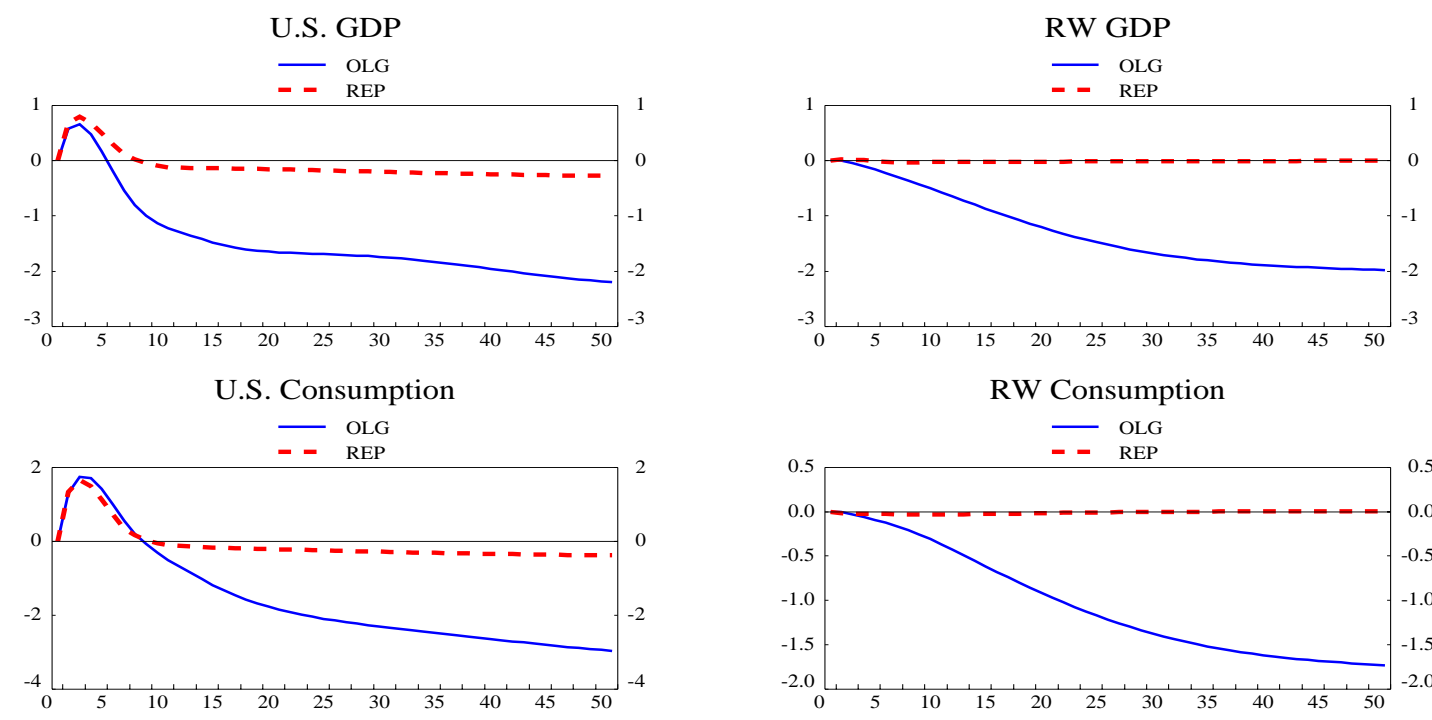

RW Consumption

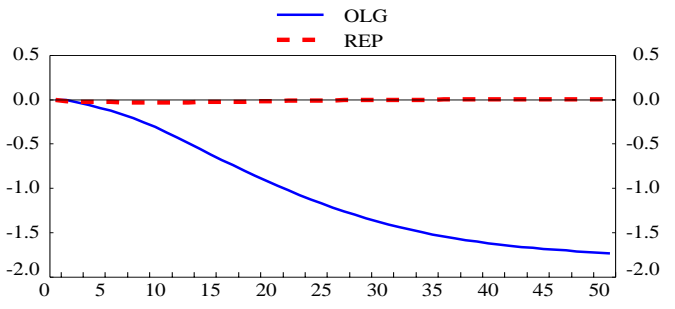

U.S. Investment

U.S. Nominal Interest Rate

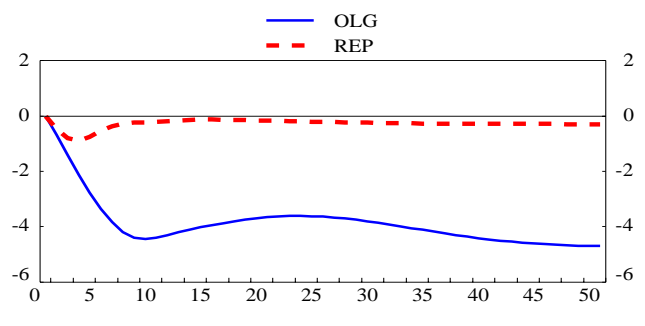

- OLG
-

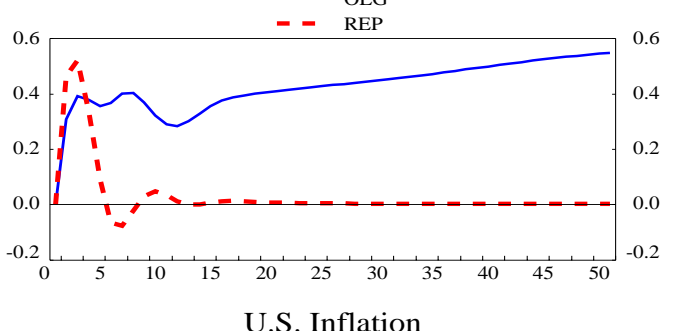

U.S. Exports
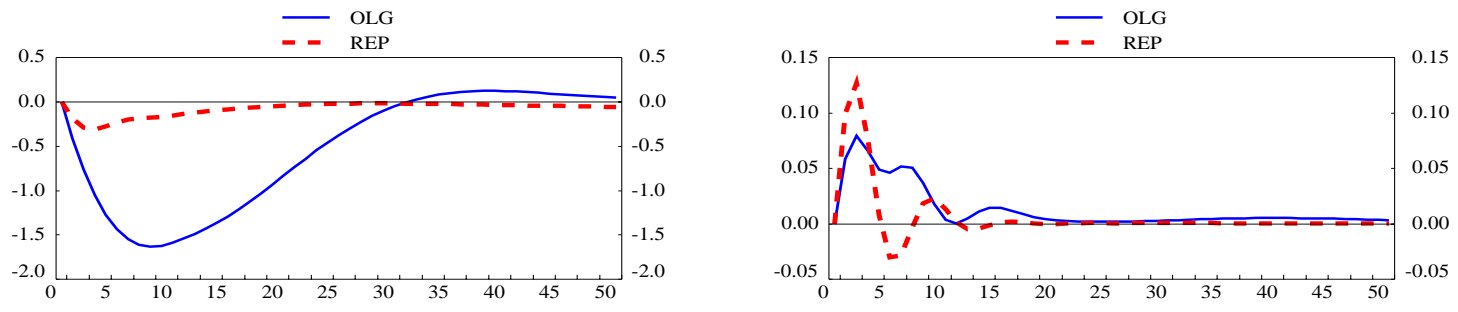

U.S. Imports

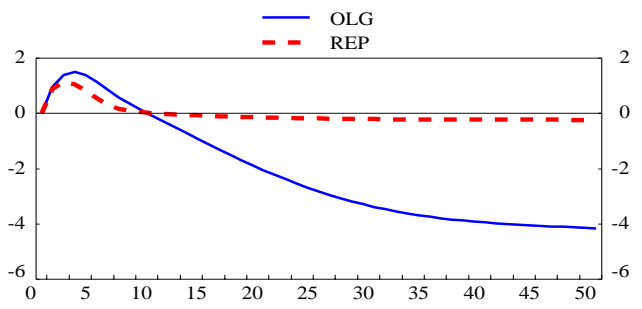

U.S. Real Exchange Rate (+ Depreciation)

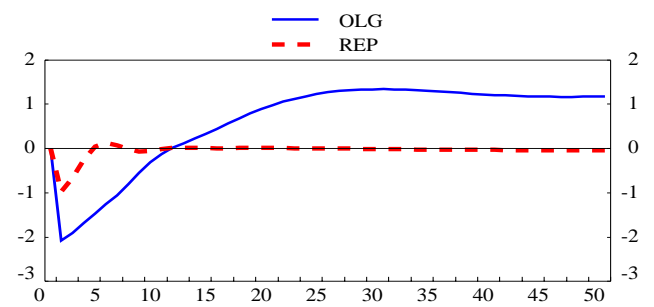


Figure 7: Cuts in Government Investment and Consumption

\section{U.S. GDP}

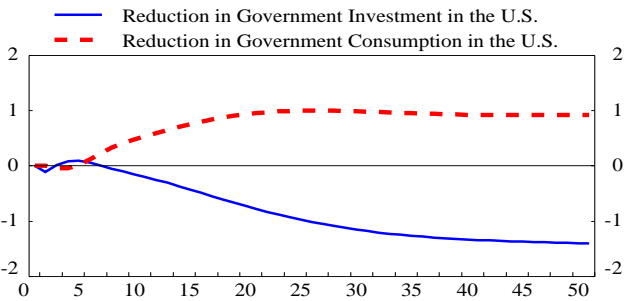

U.S. Consumption

- Reduction in Government Investment in the U.S.

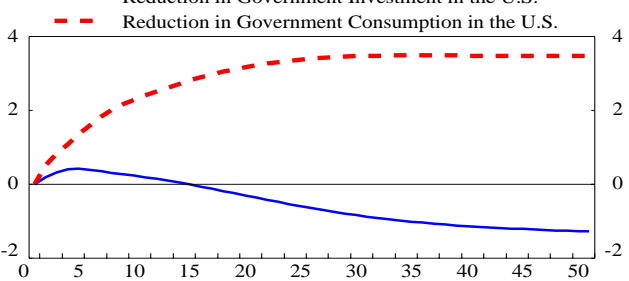

U.S. Investment

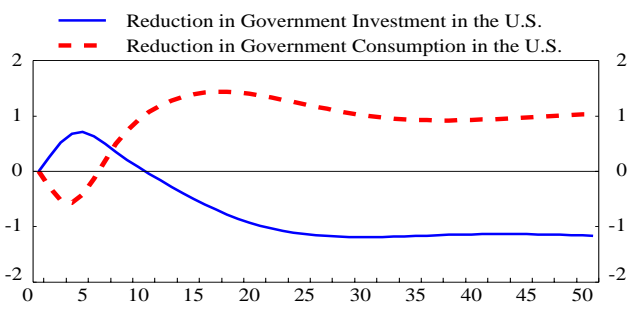

U.S. Exports

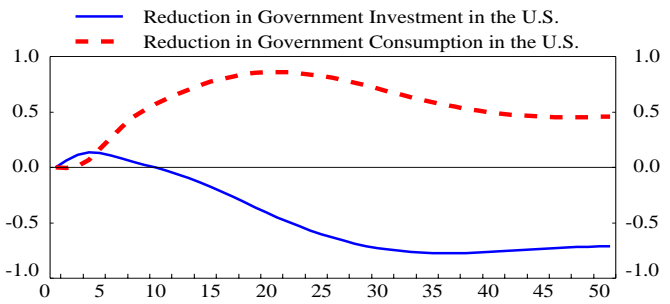

U.S. Imports

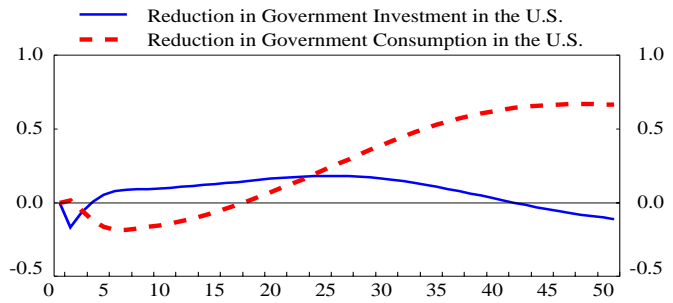

\section{RW GDP}

- Reduction in Government Investment in the U.S.

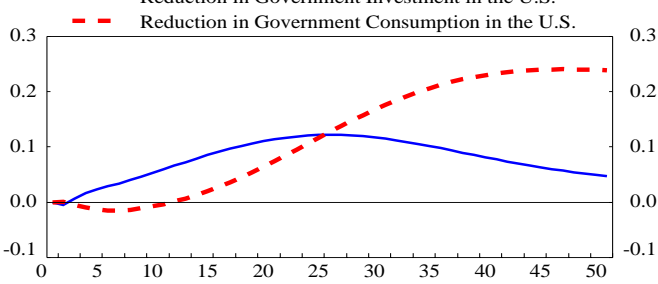

RW Consumption

- Reduction in Government Investment in the U.S.

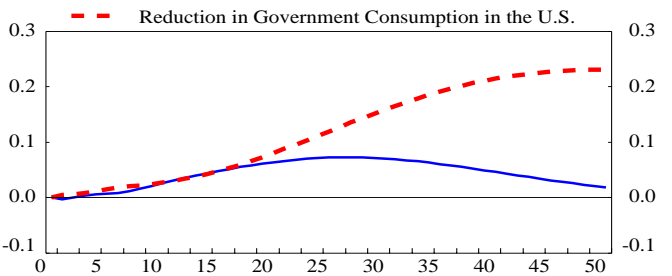

U.S. Nominal Interest Rate

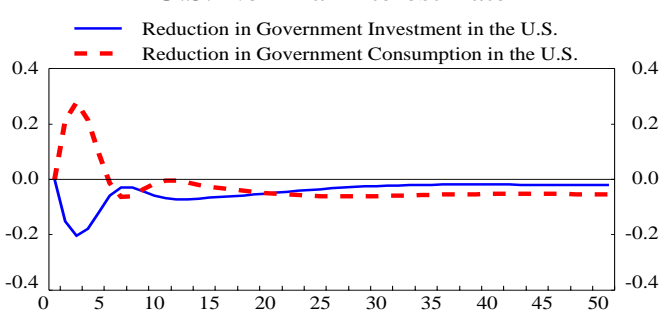

U.S. Inflation

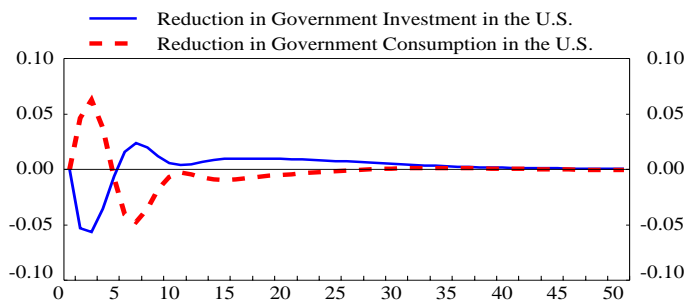

U.S. Real Exchange Rate (+ Depreciation)

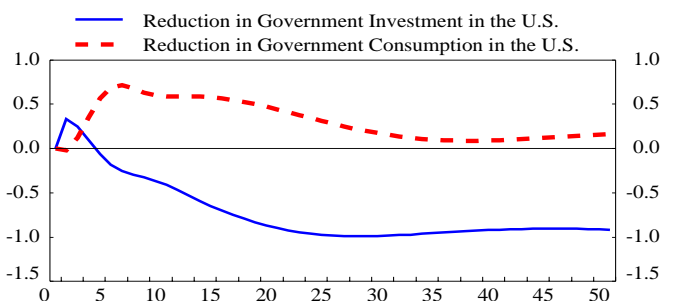


Figure 8: Lower U.S. Rate of Time Preference and Higher RW Rate of Time Preference

\section{U.S. GDP}

L Lower U.S. Private Savings Rate

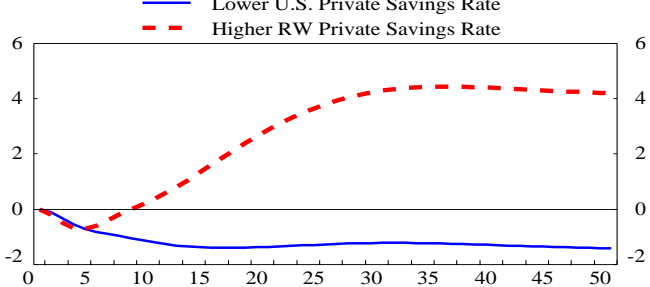

U.S. Consumption

— Lower U.S. Private Savings Rate

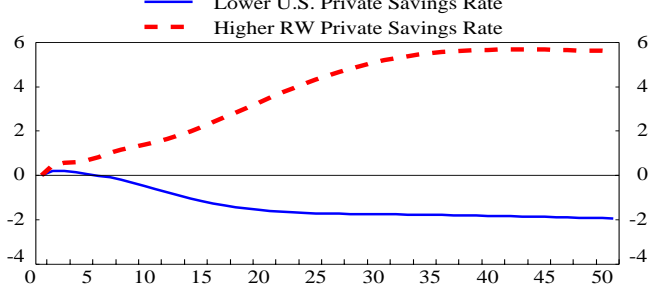

U.S. Investment

- = Lower U.S. Private Savings Rate

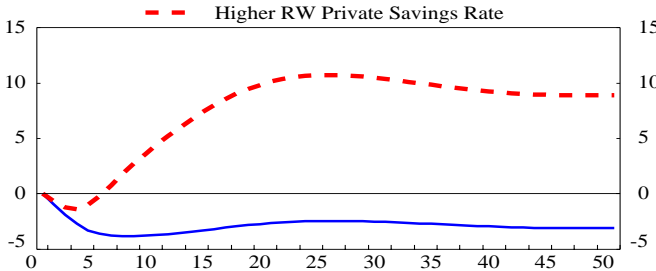

U.S. Exports

- Lower U.S. Private Savings Rate

- - Higher RW Private Savings Rate

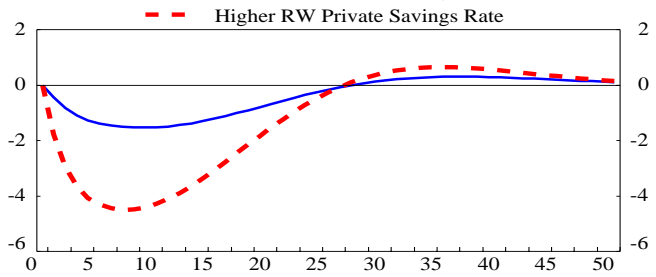

U.S. Imports

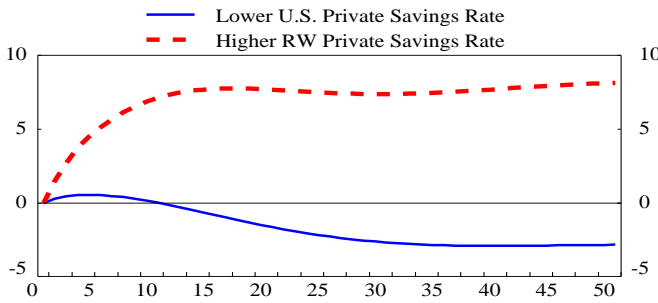

\section{RW GDP}

_ Lower U.S. Private Savings Rate

- - Higher RW Private Savings Rate

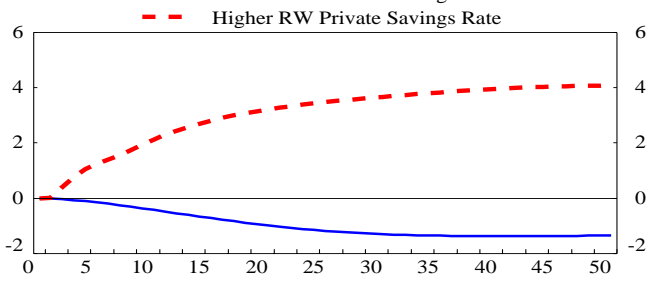

RW Consumption

_ Lower U.S. Private Savings Rate

- - Higher RW Private Savings Rate

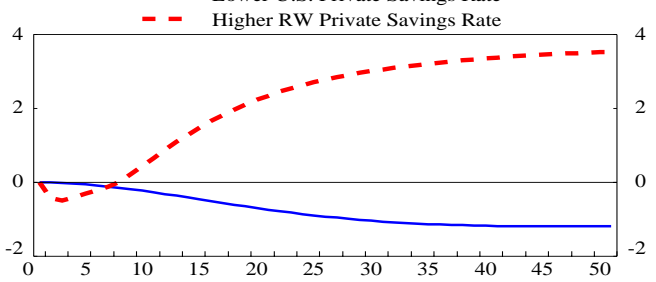

U.S. Net Foreign Liabilities Ratio

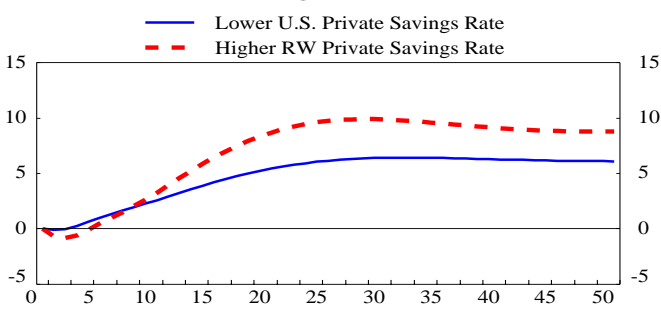

U.S. Real Interest Rate

— Lower U.S. Private Savings Rate

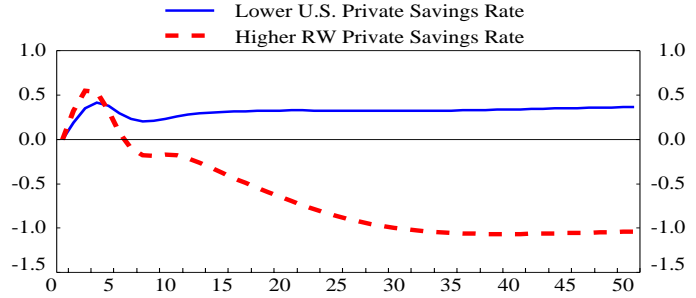

U.S. Real Exchange Rate (+ Depreciation)

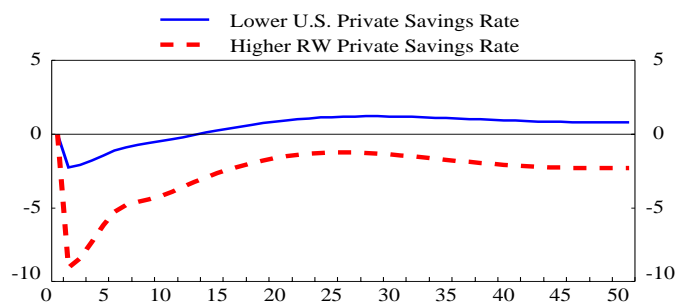




\section{References}

Aschauer, D.A. (1989), "Does Public Capital Crowd Out Private Capital?", Journal of Monetary Economics, 24, 171-188.

Aschauer, D.A. (1998), "How Big Should the Public Capital Stock Be?", Jerome Levy Institute, Policy Brief No. 43.

Bayoumi, T. and Sgherri, S. (2006), "Mr. Ricardo's Great Adventure: Estimating Fiscal Multipliers in a Truly Intertemporal Model", IMF Working Paper Series, $\mathrm{WP} / 06 / 168$.

Bernanke, B. (2005), "The Global Saving Glut and the U.S. Current Account Deficit", March 15 speech, available at http:// www.federalreserve.gov/ boarddocs/ speeches/ $\underline{2005 / .}$

Betts, C. and Devereux, M. (2001), "The International Monetary Transmission of Monetary and Fiscal Policies in a Two-Country Model", in: M. Obstfeld and G. Calvo, eds., Essays in Honor of Robert A. Mundell. Cambridge: MIT Press.

Blanchard, O.J. (1985), "Debt, Deficits, and Finite Horizons", Journal of Political Economy, 93, 223-247.

Blanchard, O.J. and Perotti, R. (2002), "An Empirical Characterization of the Dynamic Effects of Changes in Government Spending and Taxes on Output", Quarterly Journal of Economics, 117 (4), 1329-1368.

Buiter, W.H. (1981), "Time Preference and International Lending and Borrowing in an Overlapping-Generations Model", Journal of Political Economy, 89, 769-797.

Caselli, P. (2001), "Fiscal Consolidation Under Fixed Exchange Rates", European Economic Review, 45 (3), 425-450.

Chang, Y. and Kim, S.-B. (2005), "On the Aggregate Labor Supply", Federal Reserve Bank of Richmond Economic Quarterly, 91(1), 21-37.

Chinn, M., 2005, "Getting Serious about theTwin Deficits",Council on Foreign Relations, Special Council Report No. 10.

Chinn, M. and Ito, H., 2005, "Current Account Balances, Financial Development and Institutions: Assaying the World 'Savings Glut', ,NBER Working Paper No. 11761.

Chinn, M. and Lee, J., 2005, "Three Current Acount Balances: A 'Semi-Structuralist' Interpretation", NBER Working Paper No. 11853.

Chinn, M. and Steil, B., 2006, "Why Deficits Matter", The International Economy Magazine, Summer, 18-23.

Corsetti, G. and Pesenti, P. (2001), "Welfare and Macroeconomic Interdependence", Quarterly Journal of Economics, 116, 421-445. 
Engen, E.M. and Hubbard, R.G. (2004), "Federal Government Debt and Interest Rates", NBER Macroeconomics Annual, 19, 83-138.

Erceg, C., Guerrieri, L. and Gust, C. (2005a), "SIGMA: A New Open Economy Model for Policy Analysis", Working Paper, Federal Reserve Board.

Erceg, C., Guerrieri, L. and Gust, C. (2005b), "Expansionary Fiscal Shocks And The Trade Deficit", International Finance Discussion Paper 825, Board of Governors of the Federal Reserve System.

Faruqee, H., Laxton, D., Muir, D. and Pesenti, P. (2005), "Smooth Landing or Crash? Model-Based Scenarios of Global Current Account Rebalancing", NBER Working Paper No. 11583.

Fatas, A., and Mihov, I. (2001), "The Effects of Fiscal Policy on Consumption and Employment: Theory and Evidence", CEPR Discussion Paper 2060.

Ferrero, A. (2006), "Demographic Trends, Fiscal Policy and Trade Deficits", Working Paper, New York University.

Frenkel, J.A., and Razin, A. (1992), Fiscal Policies and the World Economy, Second Edition. Cambridge: MIT Press.

Gali, J., López-Salido, J.D. and Vallés, J. (2007), "Understanding the Effects of Government Spending on Consumption", Journal of the European Economic Association, 5(1), 227-270.

Ganelli, G. (2005), "The New Open Economy Macroeconomics of Government Debt", Journal of International Economics, 65(1), 167-184.

Ganelli, G. (2003), "Useful Government Spending, Direct Crowding-Out and Fiscal Policy Interdependence", Journal of International Money and Finance, 22 (1), 87-103.

Ganelli, G., and Lane, P.R. (2002), "Dynamic General Equilibrium Analysis: The Open Economy Dimension", in: S. Altug, J. Chadha, C. Nolan, eds., Dynamic Macroeconomic Analysis. Cambridge: Cambridge University Press.

Ghironi, F. (2000a), "Macroeconomic Interdependence Under Incomplete Markets", Working Paper, Boston College.

Ghironi, F. (2000b), "Understanding Macroeconomic Interdependence: Do We Really Need to Shut Off the Current Account?", Mimeo, Boston College.

Hooper, P. and Marquez, J. (1995), "Exchange Rates, Prices, and External Adjustment in the United States and Japan", in: Kenen, P., ed., Understanding Interdependence, Princeton University Press, Princeton, NJ, 107-168.

Hooper, P., Johnson, K. and Marquez, J. (2000), "Trade Elasticities for the G-7 Countries", Princeton Studies in International Economics, 87. 
Ireland, P. (2001), "Sticky-Price Models of the Business Cycle: Specification and Stability", Journal of Monetary Economics, 47, 3-18.

Kamps, C. (2004), "New Estimates of Government Net Capital Stocks for 22 OECD Countries 1960-2001", IMF Working Paper Series, WP/04/67.

Kopcke, R., Tootell, G. and Triest, R., eds., 2006, The Macroeconomics of Fiscal Policy, Cambridge and London: MIT Press.

Kumhof, M. and Laxton, D. (2006), "How Will Global Imbalances Adjust?", Box 1.3 of Chapter 1 of the September 2006 IMF World Economic Outlook.

Laubach, T. (2003), "New Evidence on the Interest Rate Effects of Budget Deficits and Debt", Finance and Economics Discussion Series 2003-12, Board of Governors of the Federal Reserve System.

Laxton, D. and Milesi-Ferretti, G.-M. (2005), "How Will Global Imbalances Adjust?", Appendix 1.2 of Chapter 1 of the September 2005 IMF World Economic Outlook.

Laxton, D. and Pesenti, P. (2003), "Monetary Rules for Small, Open, Emerging

Economies", Journal of Monetary Economics, 50(5), 1109-1152.

Ligthart, J.E. and Suárez, R.M.M. (2005), "The Productivity of Public Capital: A Meta Analysis", Working Paper, Tilburg University.

Mendoza, E. (2005), "Real Exchange Rate Volatility and the Price of Nontradables in Sudden-Stop-Prone Economies", NBER Working Paper No. 11691.

Obstfeld, M., and Rogoff, K. (1995), "Exchange Rate Dynamics Redux", Journal of Political Economy, 103, 624-660.

Obstfeld, M., and Rogoff, K. (1996), Foundations of International Macroeconomics. Cambridge: MIT Press.

Orphanides, A. (2003), "Historical Monetary Policy Analysis and the Taylor Rule", Journal of Monetary Economics, 50, 983-1022.

Pencavel, J. (1986), "Labor Supply of Men", in: O. Ashenfelter and R. Layards, eds., Handbook of Labor Economics, Vol. 1. Amsterdam: North Holland.

Straub, R. and Tchakarov, I. (2006), "Assessing the Impact of Change in Composition of Public Spending: A DSGE Approach", Working Paper.

Truman, E., 2006, "Budget and External Deficits: Not Twins but the Same Family," in: Kopcke, R., Tootell, G. and Triest, R., eds., The Macroeconomics of Fiscal Policy, Cambridge and London: MIT Press.

Weber, C.E. (2002), "Intertemporal Non-Separability and "Rule of Thumb" Consumption", Journal of Monetary Economics, 49(2), 293-308.

Weil, P. (1989), "Overlapping Families of Infinitely-Lives Agents", Journal of Public 
Economics, 38, 183-198.

Woodford, M. (2003), Interest and Prices: Foundations of a Theory of Monetary Policy. Princeton: Princeton University Press. 